\title{
LA ANTIGÜEDAD AL SERVICIO DEL REY. LA DIFUSIÓN DEL GUSTO POMPEYANO EN ESPAÑA EN EL SIGLO XVIII
} Antiquity at the service of the king. Diffusion of Pompeian
taste in Spain

M. ${ }^{\mathrm{a}}$ del Carmen ALONSO RODRÍGUEZ

Universidad Complutense de Madrid

maalon21@ucm.es

Fecha de envío: 10/12/2017

Fecha de aceptación definitiva: 15/02/2018

RESUMEN: La difusión del gusto pompeyano en España durante el reinado de Carlos III no alcanzó la notoriedad esperada. Fueron Carlos IV y María Luisa los que se interesan por las nuevas corrientes estéticas que introducen en sus residencias de campo. La llegada de los vaciados del Museo Herculanense en 1765, de los sucesivos volúmenes de Le Antichità di Ercolano y del llamado Servizio Ercolanese van a servir de referencia a los artistas españoles, quienes, sin embargo, siguen recurriendo a fuentes clásicas y renacentistas, como son los frescos de la Domus Áurea y las Logias de Rafael en el Vaticano. Se analizan las piezas pertenecientes a la Vajilla Herculanense adquiridas por el Museo Nacional de Artes Decorativas y su relación con los originales encontrados en Pompeya y Herculano, conservados en el museo de Portici con anterioridad a 1780.

Palabras clave: Pompeya; Herculano; Portici; Carlos III; Real Fabbrica Ferdinandea; Fábrica del Buen Retiro; Antichità di Ercolano; Vajilla Herculanense; Venuti.

ABSTRACT: The diffusion of Pompeian taste in Spain during the reign of Charles III did not reach the notoriety expected. It was later on with Charles IV and María Luisa, interested by the new esthetic currents, when they introduced the Pompeian styles in their countryside residences. The arrival of the plaster casts 
from the Herculanese Museum in 1765, of the volumes of Le Antichità di Ercolano and finally the so-called Servizio Ercolanese, served as a reference to Spanish artists who at that time continued to resort to classical and renaissance sources such as the frescoes of the Domus Aurea and Raphael's Vatican Loggias. This article analyzes pieces from the Herculaneum porcelain service, acquired by the National Museum of Decorative Arts and traces their relationship to the originals found in Pompeii and Herculaneum preserved in the museum of Portici before 1780 .

Key words: Pompeii; Herculaneum; Portici; Carlos III; Real Fabbrica Ferdinandea; Buen Retiro Porcelain Factory; Antichità di Ercolano; Herculaneum service; Venuti.

El llamado "año sin rey» permitió a Carlos III preparar lo que iban a ser las líneas fundamentales del gobierno del reino de las Dos Sicilias. Al Consejo de Regencia que habría de asesorar a Ferdinando IV le quedaba un margen de maniobra estrecho, ya que todo había sido diseñado para ser cumplido minuciosamente ${ }^{1}$. Entre las cosas que el monarca dejaba atrás, después de veinticinco años de reinado, se encontraba el proyecto anticuario que finalmente había conseguido formular, gracias al nombramiento de Bernardo Tanucci como secretario de Estado en 1755. Tras largos años de titubeos, intentos fallidos y fracasos, la estrecha colaboración con el secretario de Estado había empezado a dar sus frutos ${ }^{2}$. Así, cuando regresa a España en 1759, estaba ya editado el primer ejemplar de la serie titulada Le Antichità di Ercolano Esposte, dedicado a las pinturas, y dejaba en marcha el segundo. Este primer volumen, al que le seguirían otros seis, era la presentación pública de los descubrimientos arqueológicos iniciados en el otoño de 1738 en la localidad de Resina, próxima al Real Sitio de Portici. En él se ofrecía una selección de estampas de excelente calidad de las pinturas reunidas durante veinte años de excavación y reproducidas con una firme voluntad de fidelidad al original. La imposibilidad de publicar en color la pintura herculanense dificultaba imaginar los originales, pero a cambio proporcionaba un novedoso repertorio de motivos, cuya difusión e influencia en las artes decorativas sería ampliamente utilizado por los adornistas durante más de un siglo ${ }^{3}$. La edición patrocinada por el rey de Nápoles ampliaba considerablemente el corpus conocido de pintura romana formado fundamentalmente por la Domus Aurea y su interpretación en

1. Knight, Carlo. Carteggio San Nicandro-Carlo III, Il periodo della Reggenza (1760-1767). Nápoles, 2009, cap. III. III, p. CXXXV.

2. Alonso Rodríguez, M. ${ }^{a}$ del Carmen. "La Política cultural de las Dos Sicilias y la publicación de los descubrimientos arqueológicos». Revista de Historiografía, 2/2012, n. ${ }^{\circ}$ 17, IX, pp. 70 y ss.

3. Le Antichità di Ercolano Esposte (en adelante $A d E$ ). La serie está formada por ocho volúmenes, dedicados cuatro a las pinturas, dos a los bronces y uno a lucernas y candelabros. AdE I. 1757; $A d E$ II. 1760; $A d E$ III. 1762; $A d E$ IV. 1765; $A d E$ V. 1767; $A d E$ VI. 1771; $A d E$ VII. 1779. AdE VIII. 1792. 
las Logias Vaticanas hecha por Rafael y sus colaboradores Giovanni da Udine y Pierino del Vaga ${ }^{4}$.

En 1748, al poco tiempo de iniciarse las excavaciones en Pompeya, tuvo lugar el descubrimiento de la Villa de Cicerón, llamada así según la costumbre de la época de atribuir las mansiones a personajes famosos. Los frescos de esta casa tendrán una gran aceptación en la ornamentación de salones y gabinetes de los años siguientes. Son escenas con bailarinas, ménades, centauros, centauras y silenos que flotan sobre un fondo negro y cuyo eco, como veremos más adelante, llegará a final de siglo hasta el Salón de Baile de la Casita del Labrador. Se publicaron en el primer y tercer volumen de Le Antichità di Ercolano, aparecidos respectivamente en 1757 y $1764^{5}$. Para entender el impacto de esta obra hay que tener en cuenta que la mayoría de los dibujos hechos hasta el momento procedían de la memoria de los visitantes que, según era costumbre, los realizaban en una hostería próxima al museo de Portici ${ }^{6}$. Los bocetos que se incluyen en los libros de Bellicard y Cochin, Caylus y tantos otros están hechos así. Este sistema de confiar en la memoria creaba algunos problemas como es el caso de un busto de Demóstenes copiado por Mengs y publicado por Winckelmann, que resultó más parecido a otro retrato de la colección Albani que al original encontrado en la Villa de los Papiros ${ }^{7}$. A Mengs la reaparición de este dibujo en la edición francesa de la Carta de Winckelmann al conde de Brühl sobre los descubrimientos herculanenses le preocupó bastante, puesto que para entonces ya estaba en Madrid como pintor de Cámara y era sobradamente conocido el disgusto regio cuando no se respetaba la precedencia a la Academia Herculanense.

Todas estas trabas para copiar los fondos del museo contribuían a que la edición de cada uno de los volúmenes de Le Antichità se recibiese con una mezcla de expectación pero también de cansancio porque, como hemos dicho, el tiempo transcurrido desde su descubrimiento era para los anticuarios excesivo, aunque no tanto para aquellos que sabrían utilizar las estampas como inspiración para recrear todo tipo de objetos de la vida cotidiana. Para Tanucci y los miembros de la Academia la posesión regia se extendía no solo al objeto material propiamente dicho, sino a su reproducción por cualquier medio. Los académicos argumentaban que

4. En el Gabinete de Dibujos de la RABASF se conserva un ejemplar perteneciente a la colección del monasterio de Valparaíso con diversos estudios de grutescos atribuido a los mencionados artistas. D-252, Valparaíso, t. III, p. 81.

5. Le Pitture antiche di Ercolano e contorni incise con qualche spiegazione, AdE, I, Nápoles, 1757, láms. XVII-XX, bailarinas; láms XXV-XXVIII centauros, centauras y ménades; AdE, III, 1762, lám. XXXI, bailarina.

6. Allroggen Bedel, Agnes. "L'Antico e la politica culturale dei Borbone». En Herculanense Museum. Laboratorio sull'antico nella Reggia di Portici. Nápoles, 2008, p. 61.

7. Museo del Louvre, inv. Ma 237 (MR 458). Winckelmann, Johann Joachim. Lettre de M. l'abbé Winckelmann, antiquaire de Sa Sainteté, à Monsieur le Comte de Brübl, chambellan du roi de Pologne... sur les découvertes d'Herculanum. París, 1764, p. 39, lám. s. n. 
solamente la obra del rey estaba en condiciones de garantizar la autenticidad del repertorio publicado ${ }^{8}$. En ese contexto se entiende que fuesen bien recibidos los viajeros que llegaban a Nápoles desde todas partes de Europa y cuya curiosidad contribuía a la glorificación de la imagen de la monarquía. Se daba por descontado que del museo se llevarían la impresión del importante trabajo de recuperación del pasado clásico que se estaba realizando y que respetarían el hecho de que su publicación era un derecho exclusivo del propietario o de aquellos a quienes él tuviese a bien designar. Las visitas de eruditos, literatos, anticuarios, pintores y demás artistas en general no eran tan bien acogidas y su director, Camilo Paderni, se encargaba de hacérselo saber persiguiendo a todos aquellos que se atrevían a hacer algún boceto de lo que estaba expuesto. Se iniciaba aquí la costumbre de algunos museos, vigente hasta nuestros días, de obstaculizar la reproducción de los fondos que custodian. Paradójicamente, la prohibición establecida en el museo de Portici fue causa de gran escándalo en el siglo XVIII.

Para saber de dónde procedían las pinturas, esculturas, pavimentos, bronces y demás fondos del Museo Herculanense y para establecer qué es lo que podían haber visto los viajeros del siglo XVIII, tanto allí como en Pompeya, puesto que el acceso a Herculano a través de galerías subterráneas era muy restringido, es necesario revisar dónde y cuándo se habían excavado. En Herculano las excavaciones comprenden el Teatro, la llamada Basílica, la Casa del Esqueleto, la Palestra, la Casa de los Ciervos, la Casa del Atrio de Mosaico, la Casa de la Columnata Toscana y la Villa de los Papiros. En Pompeya la citada Villa de Cicerón, el Anfiteatro, los Praedia de Iulia Felix, la Casa del Ninfeo, la Casa de la Diana Arcaizante, la necrópolis de la Puerta de Herculano, el Teatro, el Odeón, el templo de Isis, el Cuartel de Gladiadores, el Foro Triangular, la Casa de José II, la Casa de las Vestales, la Villa de Diomedes, la Casa del Cirujano, la Casa de Salustio y, cuando muere Carlos III en diciembre de 1788, se estaba excavando una fábrica de jabón. En Estabia los trabajos arqueológicos incluyen la Villa de San Marcos y la de Ariadna, diversos puntos de la colina de Varano y una almazara9 . Esta relación, que no pretende ser exhaustiva, es fundamental para reconstruir el corpus de iconográfico disponible de los llamados motivos pompeyanos, pero también para entender que ningún otro hallazgo que no esté comprendido en lo explorado hasta ese momento es válido para sacar conclusiones sobre la influencia de las ciudades vesubianas en la formación del gusto neoclásico.

Para algunos autores, tras la partida de Carlos III, tanto el museo como las excavaciones pasaron a un segundo plano siendo prioritaria la edición de las antigüedades. Esta interpretación es discutible ya que desde España su promotor solo podía influir en los aspectos dedicados a su publicación, puesto que las decisiones

8. TANUCCI, Bernardo. Epistolario, IX. Roma, 1985, p. 872, n. 9.

9. Pagano, Mario y PRISCIANDARO, Raffaele. Studio sulle provenienze degli oggetti rinvenuti negli scavi borbonici del Regno di Napoli. Nápoles, 2006, vol. I. 
sobre el Museo Herculanense y sobre los lugares en los que era más oportuno excavar era necesario tomarlas estando presente y conociendo las circunstancias concretas que se sucedían a diario. El rey desde la distancia supervisa, presiona y alienta al secretario de Estado consiguiendo que salgan, además de las pinturas, otros dos tomos dedicados a los bronces ${ }^{10}$. Mientras tanto el llamado Ercolano o Herculano lo concedía el rey a aquellos que se lo pedían, y a lo largo de los años, los siguientes ejemplares llegarán a España en cantidades apreciables y se distribuirán entre los miembros de la nobleza, eruditos, bibliotecas y se facilitará igualmente a determinados artistas ${ }^{11}$. Formaba parte de la crítica ilustrada el afirmar que la obra no circulaba con regularidad por el hecho de que no se vendiese, cosa que se consideraba inaceptable ${ }^{12}$. Por ello el deseo de conseguirla la revalorizaba convirtiendo su posesión en una muestra de distinción regia. La distribución a las cortes europeas se hace desde Nápoles y es Tanucci el que decide cómo se reparte en el caso de los particulares, delegando para ello en Giovanni Maria La Torre, director de la Regia Estampería. En España el reparto se hace desde la Secretaría de Estado, donde por orden superior se adjudica también de igual manera ${ }^{13}$.

Un buen informante sobre la recepción de Le Antichità es Ferdinando Galiani, secretario de Embajada de la corte napolitana en París. Era miembro de la Academia Herculanense y, entre otras muchas cualidades, contaba con la de ser un buen latinista. Galiani era autor de una obra inédita sobre las pinturas de Herculano fechada en 1756, justo un año antes de que se publique el primer volumen regio sobre el mismo tema. Se titula Pitture antiche che si conservano nella Real Villa di Portici ${ }^{14}$. En ella se incluye un dibujo con la presentación a Carlos y a María Amalia de uno de los frescos más importantes recuperados en la llamada Basílica de Herculano, que es el del centauro Quirón enseñando a Aquiles a tocar el arpa (Fig. 1) ${ }^{15}$. El manuscrito tiene un formato muy similar al de Le Antichità y está dedicado al monarca napolitano señalando que el hallazgo del tesoro de antiguos monumentos hecho en Portici no es un capricho de la fortuna, sino un

10. TanuCcI, Bernardo. Epistolario, IX. Roma, 1985, p. 539. AdE, V, De' Bronzi di Ercolano e contorni incise con qualche spiegazione, t. I. Busti. Nápoles, 1767; AdE, V, t. II, Statue. Nápoles, 1771.

11. Alonso Rodríguez, M. ${ }^{\mathrm{a}}$ del Carmen. "La empresa anticuaria de Carlos III entre Nápoles y Madrid». En Política exterior y científica de un reinado ilustrado. Madrid, 2016, p. 88. TANUCCI, Bernardo. Epistolario, XIV, Nápoles, pp. 20-148.

12. TanuCci, Bernardo. Epistolario, IX. Roma, 1985, p. 105, sobre la imposiblidad de vender y cómo se distribuye. Sobre el reparto disparatado que se hizo en Venecia por parte del embajador Finochietti, ibid., p. 778.

13. D'IorIo, Aniello. "La Stamperia reale dei Borbone di Napoli: origine e consolidamento». En Editoria e cultura a Napoli nel XVIII secolo. Nápoles, 1998, pp. 385 y ss. MANSI, Maria Gabriella. "Libri del Re. Le antichità di Ercolano esposte». En Herculanense Museum. Laboratorio sull'antico nella Reggia di Portici. Nápoles, 2008, pp. 138 y ss. Archivo Histórico Nacional, Estado, leg. 3927. Agradezco la noticia sobre esta documentación al investigador Jaume Ramón Estrany.

14. Società Napoletana de Storia Patria (en adelante SNSP), Nápoles, mss. 31.C,10.

15. AdE, I, 1757, lám. VIII. Dibujo de Francisco La Vega y grabado de Rocco Pozzi. 
justo premio a la maravillosa o casi divina virtud del mismo ${ }^{16}$. Son de Galiani las noticias de que Le Antichità interesaba sobre todo al género de los adornistas y explica muy bien como uno de los cuadros reproducidos en el tercer volumen de las pinturas, conocido como La Vendedora de Amorcillos, lo había visto copiado en más de diez casas ${ }^{17}$. El original había aparecido en la Villa de Ariadna de Estabia el 13 de junio de 1759, pocos meses antes del regreso de los reyes a España ${ }^{18}$. De entre las muchas versiones de esta pintura, sobresale la del pintor Joseph Marie Vien, que tuvo gran éxito en el salón de 1763 en Paris ${ }^{19}$.

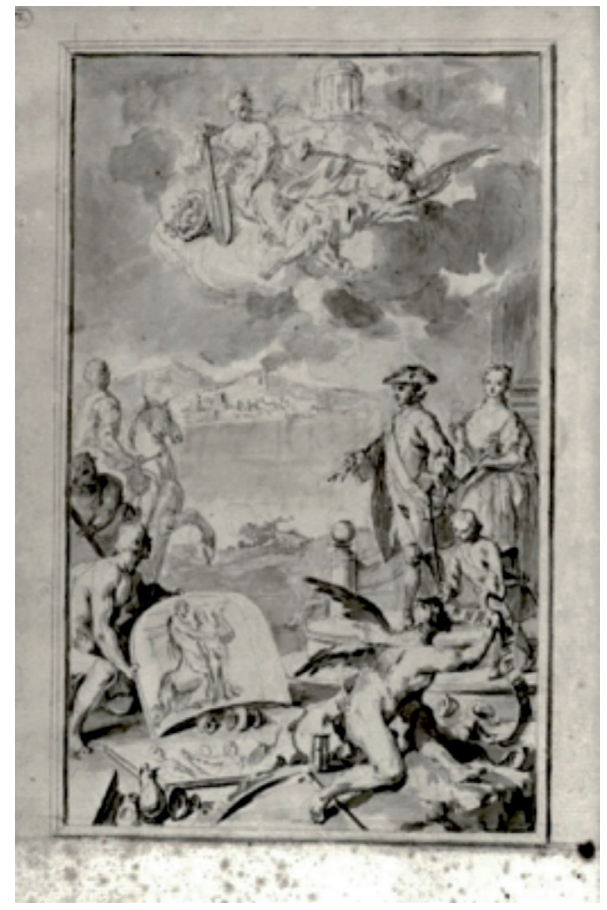

Fig. 1. Carlos y María Amalia asistiendo a los descubrimientos de Herculano, 1756 (SNSP).

16. SNSP, mss. 31.C,10, fol. II. RAPISARDA, Stefano, "Notizia biográfica». D'ÉPINAY, Luise y GaLIANI, Ferdinando. Epistolario 1769-1772. Palermo, 1996, pp. 39-40.

17. AdE, VII, lám. VII. Bologna, Ferdinando. "La Riscoperta di Ercolano e Pompei nella cultura artistica del settecento europeo». En Rediscovering Pompei. Roma, 1990, p. 78.

18. Bragantini, Irene y SAmPaOlo, Valeria. La pittura pompeiana. Nápoles, 2009, pp. 146-147.

19. Grell, Chantal y MiCHEL, Christian. "Erudits hommes de lettres et artistes en France au XVIII siècle face aux découvertes d'Herculanum». En Ercolano 1738-1988: 250 anni di ricerca archeologica. Nápoles, 1993, pp. 141-142. 
La posibilidad de editar en color las pinturas procedentes de Herculano, Pompeya y Estabia interesaba bastante a la Academia Herculanense, motivo por el que Tanucci encargó al secretario de Embajada que investigase en París cómo era el proceso de la estampación en color. La conclusión de Galiani fue desaconsejar el método, como queda detallado en su respuesta en abril de $1763^{20}$. Algunos otros artistas se ofrecerán para grabar las pinturas de Herculano con sus colores auténticos, como es el caso del pintor y grabador Johann Friedrich Reiffenstein en $1765^{21}$. Giovanni Gaetano Bottari, conservador de la Biblioteca Vaticana y experto anticuario, escribirá también a Tanucci sobre esta opción y le envía como ejemplo una versión iluminada de Pietro Bellori hecha en París y que el secretario de Estado remite al rey para que sea quien decida sobre este asunto ${ }^{22}$. Hay que recordar que a Camillo Paderni se le habían encargado copias en color de las pinturas por si estas se desvanecían por problemas de conservación, pero no estaban destinadas a fines editoriales ${ }^{23}$. Sin embargo, la publicación oficial tan largamente esperada no resultó todo lo exitosa que el rey y Tanucci imaginaban y muy pronto surgen las críticas de anticuarios ajenos al reino de Nápoles ${ }^{24}$. En otoño de 1764, es otra vez Galiani el que avisa de que se ha traducido al francés el libro de Winckelmann y las críticas que en él se vertían sobre las excavaciones, los métodos empleados por Alcubierre, los intentos fallidos de restauración de los bronces por parte de Canart. Todo esto fue interpretado por Tanucci como un ataque directo al rey y ordenó a Cantillana que enviase un ejemplar a Madrid, tal y como figura en la correspondencia semanal ${ }^{25}$.

La inquietud por la tardanza en la difusión de resultados la compartían también otros anticuarios menos beligerantes, puesto que los hallazgos procedentes de las ciudades vesubianas servían para catalogar objetos encontrados en las excavaciones de otras áreas del mundo romano. Pero, de la misma manera que no se publicó en vida de Carlos III ninguna monografía dedicada a la escultura en mármol, tampoco hubo oportunidad de que se editase nada sobre los papiros o sobre la planimetría del teatro pese a que eran ambos asuntos muy demandados. Mientras tanto, el mundo erudito se interesaba cada vez más por los aspectos de la vida cotidiana y costumbres de los antiguos, prefiriendo las lucernas, candelabros, trípodes, sillas, banquetas y todo tipo de utensilios domésticos. Por este motivo, algunos objetos como las dos sillas curules, encontradas en 1739 en el Teatro de

20. Diodati, Luigi. Vita dell'abate Ferdinando Galiani. Nápoles, 1788, p. 32.

21. Strazzullo, Franco. Le manifatture d'arte di Carlo di Borbone. Nápoles, 1979, pp. 320-323.

22. El 12 de abril de 1763, Tanucci resume al rey las dificultades para estampar en color. TANUCCI. Epistolario, XII. Nápoles, 1997, p. 101.

23. Alonso Rodríguez, M. ${ }^{a}$ del Carmen. "Documentos para el estudio de las excavaciones de Herculano, Pompeya y Estabia en el siglo XVIII bajo el patrocinio de Carlos III». En Bajo la cólera del Vesubio. Testimonios de Pompeya y Herculano en la época de Carlos III. Valencia, 2004, p. 64.

24. TanuCCI, Bernardo. Epistolario, IX. Roma, 1985, p. 835.

25. TanucCI, Bernardo. Epistolario, XIV. Nápoles, pp. 378 y 402. 
Herculano, publicadas respectivamente por el conde Caylus y Francesco Piranesi (Fig. 2), pasan a convertirse en modelos de referencia para la fabricación de mobiliario, cuando ya los intereses científicos se orientaban hacia el mundo griego al que se empezaba a acceder desde mediados del siglo XVIII ${ }^{26}$. De forma paralela se incrementa la curiosidad por los vasos griegos de la Campania, considerados entonces de origen etrusco, muy valorados por su doble función, tanto como objetos a coleccionar y como fuente de episodios mitológicos. Ese es el motivo por el que se les asigna un lugar privilegiado en las bibliotecas como complemento de los textos clásicos que albergan las mismas. Siguiendo esta moda, José Nicolas de Azara distribuirá este tipo de piezas por su biblioteca romana ${ }^{27}$.

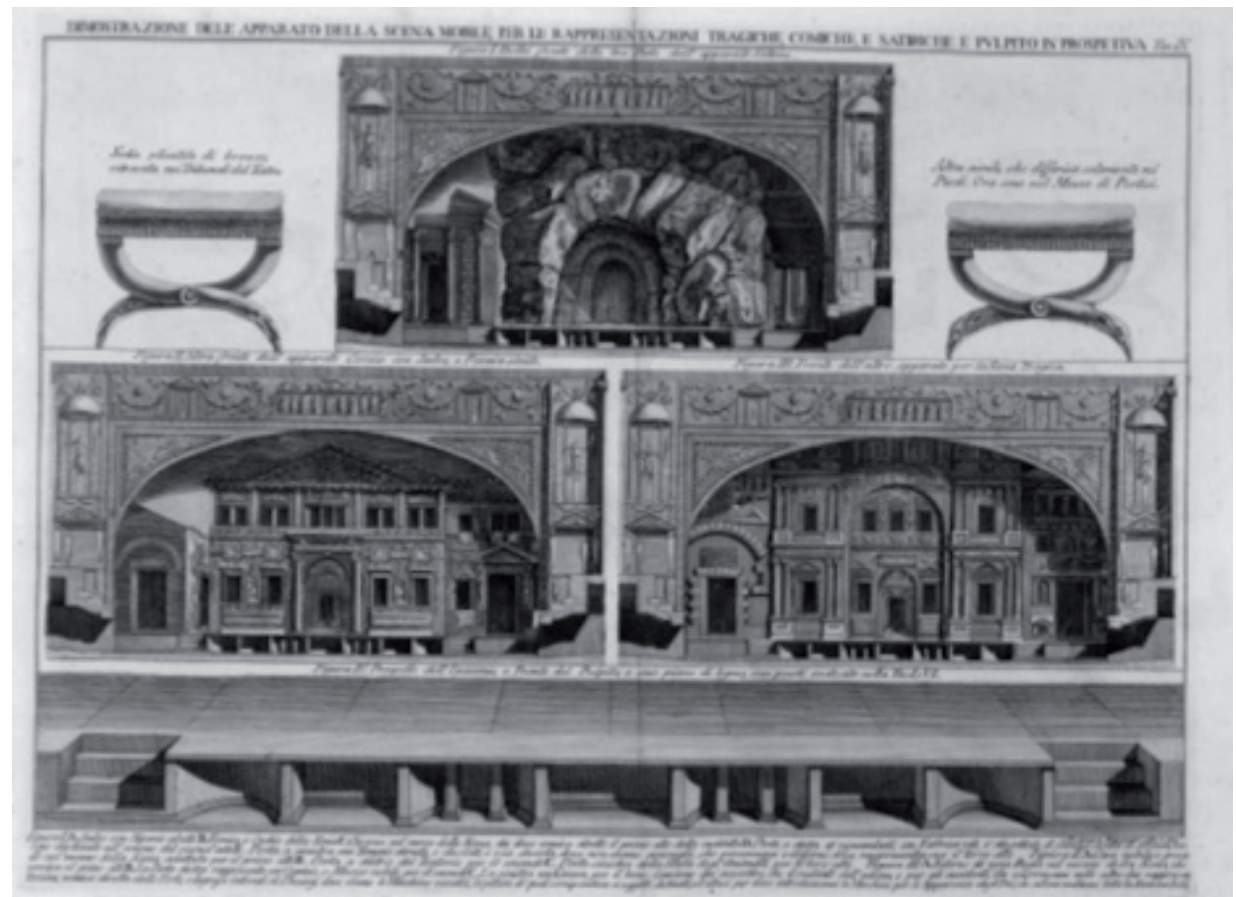

Fig. 2. Sillas curules. Il Teatro di Ercolano. F. Piranesi, 1783.

26. Aparecieron los primeros fragmentos el 15 de enero de 1739 y se interpretaron como una cornucopia. Existía un grabado inédito hecho en la Real Stamperia. SCHAEFER, Tomas. "Le "sellae curules" del Teatro di Ercolano". Cronache Ercolanesi, 1979, 9, pp. 145 y ss. PIRANESI, Francesco. Il Teatro di Ercolano. Roma: 1783, lám. IX. PAGANo y Prisciandaro. Op. cit., p. 351, n. ${ }^{\circ} 171$ a-b.

27. JORDÁn DE URRíes, Javier. "La embajada de José Nicolás de Azara y la difusión del gusto neoclásico». En Roma y España un crisol de la cultura europea en la Edad Moderna. Madrid, 2007, pp. $18-19$ 
En otras ocasiones hemos descrito las instrucciones dadas por el rey sobre cómo y dónde excavar, asunto sobre el que no nos detendremos aquí, aunque es necesario recordar que el fin de las excavaciones era aumentar los fondos del Museo Herculanense y recuperar obras de calidad para ser publicadas y difundidas a mayor gloria de su promotor. El museo que estaba formando y su engrandecimiento será uno de los temas que más le preocupará. Para proteger sus fondos y evitar la extracción de piezas fuera del reino y que cayesen en manos de particulares, se había legislado al respecto en 1755. La voluntad de que la colección se mantuviese en su integridad hasta la mayoría de edad de su hijo es la que explica el gesto público de la devolución de un anillo con un entalle romano momentos antes de zarpar para España ${ }^{28}$. Las instrucciones dejadas al respecto de cómo se tenía que proceder eran claras y, en caso necesario, se le consultaba por carta. Bien es cierto que, aunque no era frecuente, cuando esto pasaba Carlos III expresaba su voluntad de manera firme. Sirvan como ejemplo la discusión sobre si convenía dejar in situ las pinturas del templo de Isis, la destrucción de pinturas realizada sistemáticamente por Paderni, la insistencia de Carlos Weber por hacer planos o la intromisión del emperador de Austria opinando sobre el modo de excavar y sus consecuencias ${ }^{29}$.

El regreso a España de Carlos y María Amalia en 1759 supuso enfrentarse a cambios radicales en las costumbres, en el clima, en el paisaje y la adaptación a unos palacios que no fueron del agrado de sus moradores ${ }^{30}$. La reina se quejaba amargamente a Tanucci y exponía su decepción, criticaba a su suegra, sus habitaciones en el palacio del Buen Retiro, el mal tiempo reinante Madrid en el mes de enero, el paisaje desértico de sus alrededores y también el de San Ildefonso, cosa que no es extraña acostumbrada al verdor de la campiña napolitana. En el relato de todos los inconvenientes encontrados aparece el deseo de que la llegada de Sabatini pueda resolver parte de esos problemas ${ }^{31}$. Aranjuez le gustaba algo más y es en este Real Sitio donde se instalará el primer Gabinete de Porcelana, al estilo del que había en el Palacio de Portici, empleando para ello las materias primas traídas de la fábrica de Capodimonte, aunque María Amalia no lo llegará a ver ${ }^{32}$. Por su parte, Carlos III se manifestaba más comedido en sus críticas, pero tampoco

28. D'Alconzo, Paola. L'Anello del Re. Florencia, 1993, pp. 32, 40, n. 73.

29. Alonso Rodríguez, M. ${ }^{a}$ del Carmen. "Las excavaciones de Herculano, Pompeya y Estabia en el siglo XVIII: cómo y dónde excavar». En Pompeya. Catástrofe bajo el Vesubio. Madrid, 2012, pp. 319-321.

30. SAncho, José Luis. "Carlos III de Monte en Monte». En Una corte para el rey. Carlos III y los Sitios Reales. Madrid, 2016, pp. 101-106.

31. VÁzQuez Gestal, Pablo. Verso la riforma della Spagna Il Carteggio tra Maria Amalia di Sassonia e Bernardo Tanucci. Nápoles, 2016, vol. II, Buen Retiro n. ${ }^{\circ}$ 12, pp. 90-91; Aranjuez n. ${ }^{\circ} 25$, pp. 182; Sabatini n. ${ }^{\circ} 27$, p. 200; La Granja n. ${ }^{\circ}$ 40, pp. 272-273.

32. Granados, Marian. "La porcelanas de la Real Fábrica de Su Majestad Católica». En Carlos III, Majestad y Ornato en los escenarios del Rey Ilustrado. Madrid, 2016, p. 239. 
aprobaba lo que se había hecho en el llamado Palacio Nuevo. Sin embargo, aceleró las obras necesarias para su finalización, quizá llevado por los deseos de la reina, que no podía soportar Buen Retiro. Atrás quedaba en manos de Vanvitelli la construcción de Caserta y toda comparación entre ambos edificios nos hace entender los motivos por los que el proyecto iniciado por su padre y continuado por su hermano Fernando VI no era de su agrado. Pero conociendo su carácter, su voluntad para solucionar en la medida de lo posible los errores cometidos, se entiende que intentase resolver el problema y cinco años después de haber llegado a Madrid, el 1 de diciembre de 1764, se muda a su nueva residencia, sin esperar a que esta estuviese terminada. El traslado a un edificio en el que faltaban aún por pintar una parte de las bóvedas y por acabar el Cuarto Real nos habla de su manera de actuar, del convencimiento de que su presencia hacía que las cosas funcionasen y que manifestando sus deseos personalmente conseguía de sus subordinados que los cumpliesen. Sobre este aspecto solía escribir a Tanucci cuando este le comentaba los problemas surgidos en su ausencia. Bien es verdad que el tiempo que iba a pasar allí sería relativamente breve ya que en enero se iría al palacio del Pardo y no regresaría a Madrid hasta Semana Santa, con lo cual los pintores y demás artistas involucrados en la terminación del Cuarto Real podían trabajar en su ausencia.

Carlos III delega en el conde Felice Gazzola, llegado a España para modernizar la artillería, la creación de una de las estancias más representativas como es el Salón de Embajadores. Se elige a Tiépolo para pintar su bóveda, mientras el trono, los marcos de los espejos, las consolas, los bordados de los terciopelos y el dosel se encargan en Nápoles al arquitecto Giovanni Battista Natali ${ }^{33}$. Gazzola, durante su etapa napolitana, había participado en los descubrimientos arqueológicos impulsando, entre 1746 y 1748, el estudio, planos y alzados de los templos dóricos de Paestum, empresa en la que también intervino Sabatini, que era entonces un joven ingeniero militar, y el citado arquitecto Natali. Es importante señalar que las dos personas elegidas por el rey para la adecuación del palacio y de la ciudad conocían bien la arquitectura clásica y por descontado los hallazgos de las excavaciones de Herculano, Pompeya y Estabia. Sin embargo, la arquitectura griega arcaica no se apreciaba por igual entre sus contemporáneos ya que otro arquitecto, Ferdinando Sanfelice, pensó en reutilizar las columnas de los templos de Paestum para el palacio de Capodimonte ${ }^{34}$.

No nos queda otra opción que preguntarnos cuáles eran las preferencias del rey recién llegado. Sabemos que era una persona reacia a los cambios en su

33. Sancho, José Luis. "El Salón del trono en el Palacio Real de Madrid». En Carlos III, Majestady Ornato en los escenarios del Rey Ilustrado. Madrid, 2016, pp. 209 y ss. GARCía FernÁndez, M. ${ }^{a}$ Soledad. "Trono de Carlos III", ibidem, p. 220.

34. Moleón Gavilanes, Pedro. "La difusión de la imagen de Paestum en el siglo XviII". En De Pompeya al Nuevo Mundo: la corona española y la arqueología en el siglo XVIII. Madrid, 2008, p. 94. 
entorno y muy constante en la regularidad de sus costumbres. Hay datos sobrados de ello en su correspondencia con Tanucci, con San Nicandro y con su propio hijo Ferdinando, además de las descripciones de sus contemporáneos, como el conde de Fernán Núñez. Acostumbrado a no cambiar de colaboradores, ni de ropa, ni de taza en la que beber el chocolate, no es extraño pensar que sus conceptos estéticos sobre cómo debía desarrollarse el programa decorativo estuviese firmemente solidificado en el tiempo de su matrimonio y en las preferencias de la reina. Pero al igual que sucedía en Portici, como señala Paola D’Alconzo, las antigüedades que estaban saliendo a poca distancia en Herculano no podían estar más lejos del gusto de los reyes, de su elección de los artistas y de los programas decorativos de la Reggia ${ }^{35}$. En este palacio la abundancia de los hallazgos arqueológicos, incrementados diariamente en las excavaciones, obligaron a habilitar determinados espacios para almacenar la colección, antes incluso de que se hubiese pensado en la creación de un museo. De hecho, la actitud de Carlos III ante las antigüedades es muy similar a la de las grandes familias de la nobleza italiana en la que las esculturas constituyen un patrimonio propio de príncipes y de papas, que se da a conocer mediante lujosas ediciones y que en ocasiones, siempre de forma controlada, se autoriza a que se copien. Las esculturas y pinturas recuperadas no son para el rey un campo de estudio ni de conocimiento, sino que vienen a llenar una carencia en sus colecciones napolitanas ya que, habiendo trasladado las colecciones familiares desde Parma, para no indisponerse con el Papa, había dejado en suspenso el traslado de la galería de escultura que estaba en Roma en el palacio Farnese. Este vacío fue plenamente colmado con las que comenzaron a recuperarse fundamentalmente en Herculano. Los bustos de bronce de la Villa de los Papiros se instalaron en las habitaciones de la reina, donde los vio Winckelmann, al igual que las llamadas pinturas monocromas sobre mármol procedentes de Herculano ${ }^{36}$. Pese a que a veces se ha querido ver de otro modo, no parece que el contacto con la Antigüedad se entendiese de una manera distinta a como venía haciéndose desde la época de Felipe V e Isabel de Farnesio ${ }^{37}$. La escultura formaba parte de las colecciones de los reyes, príncipes y papas que la integraban en sus palacios o jardines como ornamento de prestigio.

En cuanto a la influencia del hallazgo de las ciudades vesubianas en la arquitectura, hay que señalar que no se habían descubierto edificios importantes que pudieran aportar nuevos modelos al repertorio arquitectónico, salvo el teatro de

35. D’Alconzo, Paola. "Carlo di Borbone a Nápoli: passione archeologiche e immagine della monarchia». En Cerimoniale dei Borbone di Napoli, 1734-1801. Nápoles, pp. 131-132.

36. Bragantini y Sampaolo. Op. cit., p. 34, n. ${ }^{\circ} 166-169$.

37. Simal López, Mercedes. "Marmi per la decorazione del palazzo della Granja de San Ildefonso, residenza di Filippo V e Elisabetta Farnese». En Splendor marmoris. I colori del marmo, tra Roma e l'Europa, da Paolo III a Napoleone III. Roma, 2016, pp. 243-244. Idem. "Isabel de Farnesio y la colección real española de escultura. Distintas noticias sobre compras, regalos, restauraciones, y el encargo del "Cuaderno de Aiello"». Archivo Español de Arte, julio-septiembre, 2006, LXXIX, 315, pp. 265-270. 
Herculano, que continuaba y continúa siendo una excavación subterránea. Tampoco en Pompeya, donde lo habitual, hasta mediados de los años sesenta, era excavar y volver a enterrar puesto que se trataba de fincas rústicas que había que devolver a sus dueños en condiciones para que se pudiesen cultivar. Uno de los primeros monumentos que se deja sin cubrir será la puerta de Herculano en 1764 y al año siguiente el templo de Isis, cuyo hallazgo tuvo una gran repercusión, no tanto por su arquitectura como por las pinturas de estilo egiptizante y por su relación con los cultos orientales y mistéricos. El templo a medio excavar se publicó en 1776 en los Campi Phlegraei de William Hamilton y es la primera imagen de un edificio pompeyano en el siglo XVIII ${ }^{38}$.

Para Mario Praz el entusiasmo con que acoge Europa el descubrimiento de Herculano no significa el comienzo inmediato de una moda ${ }^{39}$. En la decoración de los Cuartos Reales tampoco juega un papel relevante la estrecha relación del rey con la Antigüedad. La creación de los Gabinetes de Porcelana en Aranjuez y en Palacio, el Salón Gasparini, el Salón del Embajadores e incluso el dormitorio regio son buena prueba de ello. Los tapices del dormitorio hechos a partir de los cartones de Guillermo Anglois, poblados de follajes de acanto, roleos, caulículos, animales diversos y guirnaldas florales enmarcando medallones de camafeos, manifiestan un estilo barroco clasicista, un conjunto lejano al espíritu neoclásico, aunque los motivos individualmente estén inspirados en elementos decorativos romanos. A principios de los años setenta, al retirarse Anglois, completa la serie José del Castillo con los mismos criterios. La opinión de Mengs sobre los cartones de Anglois fue muy favorable considerando que tenían una gran calidad acorde al lugar al que estaban destinados en el que compartirían el espacio con diez cuadros de su autoría que, según José Luis Sancho, otorgaban al dormitorio un contenido religioso coherente con la piedad del rey ${ }^{40}$. La elección del pintor sajón, que era un buen conocedor de los hallazgos arqueológicos y del museo de Portici, no supuso la introducción de nuevos repertorios en el entorno regio.

Pero ya en España no parece que el rey, en ese esfuerzo por no dejarse llevar por la nostalgia y por no mirar atrás, buscase rodearse de aquello a lo que renunció, entre otros motivos, porque cuando surgían esa clase de sentimientos los cortaba recordando que así era por voluntad divina. De hecho, los primeros tapices que encargó fueron escenas de caza de Teniers y los cuadros de este artista y los asuntos ridículos que regularmente pintaba, según la descripción de Ponz, se distribuían por doquier tanto en la pieza del retrete como en otros gabinetes ${ }^{41}$. Los retratos de los nietos napolitanos más los cuadros de Pannini de su visita al papa Benedicto XIV

38. Alonso Rodríguez. 2004, p. 70, lám. 11.

39. Praz, Mario. Gusto neoclásico. Barcelona, 1982, pp. 86 y ss.

40. SANChO, José Luis. "Real Dormitorio». En Carlos III, Majestad y Ornato en los escenarios del Rey Ilustrado. Madrid, 2016, pp. 93 y ss.

41. Ponz, Antonio. Viaje de España. Madrid, 1782, vol. VI, p. 34, n. ${ }^{\circ} 41$. 
en Roma estaban presentes como parte de su biografía. En el Cuarto Real, en la antecámara, Ponz menciona la presencia de ocho bustos de emperadores de pórfido y de emperatrices colocados sobre las mesas y alguna escultura como un niño con pileo y una Venus. Igualmente, en la pieza donde comía el rey se podían ver tres bustos de emperatrices y otro de un emperador ${ }^{42}$. Tanto la disposición sobre mesas como el tipo de piezas elegidas no supone ningún cambio ni otra forma diferente de entender la escultura clásica con relación a sus predecesores.

Poco antes de instalarse en el palacio, en diciembre de 1763, Carlos III enviaba a Camilo Paderni, conservador del Museo Herculanense, a Roma a comprar antigüedades y es indudable cuál era su destino ya que no estaba entre sus planes desmontar la colección que habían reunido sus padres en San Ildefonso. La colección real de escultura que tenía a su disposición, heredada de los Austrias, debió parecerle de poco relieve tras su experiencia napolitana y toma la decisión de comprar esculturas en el mercado romano, como habían hecho sus progenitores años antes. Eso sí, las califica de «algunas cosillas que quiero comprar», teniendo en cuenta que se trata de las estatuas del Neptuno y la Ceres, los relieves de las Ménades, los de las Erinnias y el de Prometeo, en la actualidad en el Museo del Prado ${ }^{43}$. En 1765 llegó a España Paderni con trece cajones de antigüedades más otros dieciséis con bustos y estatuas de yeso que el monarca había solicitado años antes, la mayoría de ellos procedentes de la Villa de los Papiros y que, a diferencia de las esculturas de mármol, se instalaron en el Buen Retiro ${ }^{44}$.

La colección de antigüedades se adquirió en Roma con la mediación, entre otros, de los comerciantes Belisario Amidei y Thomas Jenkins y con la inestimable colaboración de Winckelmann, comisario apostólico de Antigüedades, encargado de facilitar su salida del Estado Pontificio. De la ubicación en Palacio de este primer lote de esculturas y de algunas otras que llegaron con posterioridad, tenemos pocas noticias. Pero sin lugar a dudas hubo que restaurarlas tras un largo y complicado periplo desde Roma a Civitavecchia, de ahí a Nápoles y luego hasta Cartagena, para llegar finalmente a Madrid. Paderni permaneció en España desde junio hasta que estalla el motín de Esquilache, siendo uno de los italianos que abandona España precipitadamente ${ }^{45}$. Quizá para evitar críticas no se dieron a conocer las compras que el rey realizaba en Roma y todo hace pensar que por idénticos motivos no continuó el acopio de esculturas en el mercado italiano. No obstante, con posterioridad a estas fechas, aún llegaron algunas piezas, pero no nos consta que se hiciesen más encargos de estas características. Sí llegaron

42. Id., p. 76, p. 27, n. ${ }^{\circ}$ 33. El niño con pileo hoy en el Museo Nacional del Prado, inv. E00742.

43. Alonso Rodríguez, M. ${ }^{a}$ del Carmen. "Ecos de Herculano: Aquellas cosas que sabes que son tan de mi genio y gusto». En Corona y Arqueología en el siglo de la Luces. Madrid, 2010, p. 239.

44. Alonso Rodríguez, M. ${ }^{a}$ del Carmen. "Vaciados del siglo XVIII de la Villa de los Papiros de Herculano en la Real Academia de Bellas Artes de San Fernando". Boletín de la Real Academia de Bellas Artes de San Fernando, 2005, 100-101, p. 28.

45. AlONSO RODRígueZ. 2009, p. 241. 
algunos yesos más y todavía en 1782, en Portici, el escultor Canart mencionaba la posibilidad de enviar como regalo a Carlos III la copia de la estatua ecuestre de Marco Nonnio Balbo que se estaba formando para la Fábrica Ferdinandea ${ }^{46}$. Tenemos noticias de otra remesa de vaciados, esta vez en el reinado de Carlos IV, que quizá corresponderían a obras de la colección Farnese, que acababa de trasladarse desde Roma a Nápoles ${ }^{47}$. La elaboración de este tipo de modelos para la producción de la Fábrica Ferdinandea tiene su paralelo en la colección de yesos pertenecientes a la Fábrica del Buen Retiro, a la que probablemente se enviaron ejemplares procedentes de las citadas remesas ${ }^{48}$.

Para determinar la ubicación en Palacio de las esculturas compradas por Carlos III la información que nos proporcionan los inventarios reales y el propio Ponz es insuficiente. Dado el tipo de descripciones es difícil saber si alguno de los bustos citados en las distintas mesas del Cuarto Real pertenecen a los que trajo Paderni. Sin embargo, es más sencilla la identificación de otras esculturas, mencionadas por el mismo autor en el tercer suelo por debajo del principal, en lo que califica de almacén, donde estaban los relieves de las Ménades y los Planetas de Jongnelinck y copias de bronce encargadas por Velázquez ${ }^{49}$. Otra parte importante de las obras adquiridas en Roma para Carlos III estaban en el taller de escultura pendientes de restauración, al igual que seguían allí varias estatuas afectadas por el incendio del Alcázar, lo cual nos habla de las dificultades que hubo para rescatarlas en 1734. Lo mismo sucedía con los yesos de Velázquez, dañados en el incendio y llevados a la Casa de la Panadería, donde en 1759 seguía restaurándolos Juan Pascual de Mena $^{50}$. Volveremos a tener noticias de las esculturas de las colecciones reales en otros inventarios posteriores y no parece que el tema de su restauración se considerase un asunto prioritario. Sin embargo, sí tenemos información de que se hizo especialmente un armario para guardar algunos de los pequeños bronces enviados por Belisario Amidei. Aunque Castellanos de Losada afirma que los mosaicos de los Massimi estaban en la Real Cámara, existe un recibo de 1787 de su traslado desde el Buen Retiro a la Real Biblioteca ${ }^{51}$. Vuelve así a aparecer este palacio como el lugar en el que se conservaban los vaciados, los mosaicos y algunos vasos griegos, que se

46. STRAZZULLO, p. 264

47. 27 de septiembre de 1785. Se autoriza el embarque de veinte cajas de modelos y figuras para el príncipe de Asturias. Archivo de Estado de Nápoles, Soprintendenza Generale della Reale Azienda e delle Real Dogane, leg. 1358. 28 de abril de 1793. Se autoriza el embarque para el rey de España de cinco cajas de modelos. Ibidem, leg. 1395.

48. Parte de esta colección conservada en la RABASF ha sido estudiada por Anna Luise Hernández Pugh, que ha realizado en 2016 su TFM sobre ella.

49. PONZ, pp. 73-74, n. ${ }^{\circ} 86-87$.

50. LuZón NoguÉ, José M. ${ }^{a}$. "Germánico». En Esculturas de Velázquez para el Alcázar. Madrid, pp. 396-397.

51. Alonso Rodríguez, M. ${ }^{a}$ del Carmen. "La colección de antigüedades comprada por Camillo Paderni en Roma para Carlos III". En Illuminismo e ilustración: le antichità e $i$ loro protagonisti in Spagna e in Italia nel XVIII secolo. Roma, 2003, pp. 42 y ss. 
destinaron al Real Gabinete de Historia Natural. De esta manera, salvo las esculturas de mármol y los pequeños bronces citados, el rey no tenía en su entorno inmediato ninguna de las antigüedades que había mandado comprar.

La difusión del gusto pompeyano en España durante el reinado de Carlos III estuvo mediatizada, a diferencia de otros países europeos, por la lealtad al monarca y a su proyecto de edición de Le Antichità. Hemos visto que, desde el inicio de los descubrimientos hechos en el teatro de Herculano en 1738, Carlos III se mostró contrario a que la publicación de los hallazgos se hiciese fuera del reino y sin el control de la corte napolitana, decisión que habrá de afectar negativamente a la difusión de las excavaciones. Sin embargo, a España llegaron frecuentes noticias desde los primeros meses de trabajo pero iban dirigidas a los padres del monarca y no tuvieron mayor trascendencia. Pese al interés demostrado por Isabel de Farnesio no sucedía lo mismo en Nápoles, donde personas muy próximas al rey, como el marqués de Salas, secretario de Estado, no compartían en absoluto esta pasión anticuaria y olvidaba a veces informar o enviar documentos a su homólogo en Madrid. Algunos autores ponen en duda la capacidad de los reyes de las Dos Sicilias para entender la repercusión de los hallazgos arqueológicos, pero no cabe duda de que eran plenamente conscientes y ese es el motivo principal por el que, una vez saciada la curiosidad inicial, sostengan a lo largo del tiempo las excavaciones $^{52}$. Gracias al descubrimiento de una de las ciudades enterradas por el Vesubio, el pequeño reino del sur de Italia y su nuevo rey pasarán a un primer plano en la escena europea y todo lo relacionado con los resultados de las excavaciones se convierte en un asunto de Estado. Eso supo intuirlo su protagonista pese a ciertos titubeos iniciales provocados por algunos personajes de la corte a quienes el tema parecía motivo de irrisión ${ }^{53}$.

La llegada de la familia real a Madrid en 1759 no viene acompañada por ningún objeto procedente de las excavaciones de Herculano. En lo que a antigüedades se refiere, Carlos III regresa ligero de equipaje y tan solo trae consigo el primer tomo del Ercolano. Pero con los reyes se trasladan también muchos personajes conocedores de los descubrimientos arqueológicos e interesados por la Antigüedad, como el citado Gazzola, y con ellos los artistas que formarán el núcleo inicial de la Real Fábrica del Buen Retiro, una vez desmantelada la de Capodimonte. A este grupo se irán sumando otros llamados por el rey, que echa en falta arquitectos, pintores, escultores, logrando atraer a algunos como será el caso de Mengs, Sabatini y Andrea Pozzi. Este último va a estar relacionado con una de las pocas aficiones sedentarias de Carlos III, quien, a decir de Fernán Núñez, se

52. Moorman, Eric M. Pompeii's Ashes: The Reception of the Cities Buried by Vesuvius in Literature, Music, and Drama. Berlín, 2015, p. 21.

53. Fernández Murga, Félix. Carlos III y el descubrimiento de Herculano, Pompeya y Estabia. Salamanca, 1989, p. 28. 
entretenía tallando en marfil algunos objetos ${ }^{54}$. Había encargado a Vanvitelli que le montase un torno que le había regalado Luis XV en el Palacio Real de Nápoles y a eso se dedicaba cuando quería reflexionar en soledad sobre algún asunto determinado $^{55}$. El proceso de contratar a Pozzi fue complicado y bastante similar a las negociaciones que hubo que entablar con Mengs. Pero el deseo de traerle a Madrid era firme, aunque sus exigencias eran tales que Tanucci tuvo que recordarle que su cualificación no estaba incluida entre las tres artes liberales que se estudian en Roma en la Academia ${ }^{56}$. Pozzi va a ser el primer artista que en España se dedique a reproducir temas de la pintura herculanense y lo interesante de sus versiones en marfil es la fidelidad con la que representa las estampas grabadas, no las pinturas, dejando sin trabajar las partes perdidas en el original. El mejor ejemplo es el de Teseo venciendo al Minotauro dibujado por Francisco Lavega y grabado por su hermano Rocco Pozzi ${ }^{57}$. Se había encontrado el 12 de septiembre de 1739 en la llamada Basílica de Herculano y formaba parte de las megalografías o cuadros de gran formato que suscitaron mucho interés en el momento de su hallazgo ${ }^{58}$.

La llegada de los vaciados de esculturas del museo de Portici podría haber sido una gran oportunidad de difusión de la escultura herculanense, pero no fue así por voluntad regia, siempre a la espera de que se publicasen los bustos y las estatuas de bronce. Desde 1765 a 1775 la colección de yesos se guardó en el Buen Retiro, a salvo de curiosos y de artistas. Mengs y Felipe de Castro, conocedores de su existencia, elaboraron en 1769 un listado de los vaciados que necesitaban en la Academia para el estudio de la Antigüedad y en ellos incluían los de Herculano y Pompeya que sabían que estaban en el Buen Retiro. En esta ocasión Carlos III hizo oídos sordos a la petición de sus artistas puesto que, aunque ya estaban editados los bustos, aún faltaban las estatuas de las cuales en el Buen Retiro tenían el Hermes sentado, el Sátiro ebrio y uno de los corredores de la Villa de los Papiros. Dicha monografía aparecerá en 1771 con lo cual, cuando el rey visite la Academia de Bellas Artes de San Fernando el 30 de diciembre de 1775, será libre de donar los vaciados para

54. Fernán Núñez, Conde de. Vida de Carlos III. Madrid, 1898, tomo II, p. 52.

55. Estella Marcos, Margarita. «La Casita del Príncipe del Escorial. Sala de los Marfiles». Reales Sitios, 1978, 15, V, pp. 57-64; GonZÁlez Palacios, Alvar. "La Vajilla Ercolanese de Carlos III». En El arte en la corte de Nápoles en el siglo XVIII. Madrid, 1990, pp. 129-130; Herrero SANZ, María Jesús. «El Desengaño». En Carlos IV mecenas y coleccionista. Madrid, 2009, pp. 134-135; ROMERO ReciO, Mirella. "Pompeii in Spanish interior decoration». En Returns to Pompei. Estocolmo, 2016, pp. 57-59.

56. Tanucci. Epistolario, XII. Nápoles, 1997, pp. 140, 157. Dice Tanucci que Pozzi traía consigo unas muestras de su arte, aunque ya estaban en Madrid las dos figuras de marfil conocidas como $E l$ Pudor y El Desengaño. Herrero. Op. cit., p. 134. El 17 de mayo de 1763, Carlos III escribe «yo no soy de los que por un gusto se deja coger de las narices». CARLOS III. Cartas a Tanucci. Madrid, 1988, p. 436.

57. AdE, I, Nápoles, 1757, lám. V, pp. 21-25. Los marfiles firmados por Pozzi son el Aquiles con el centauro Quirón; Hércules y Telefo, y Apolo y Casandra. A nombre de R.V. sin que conste en el catálogo ninguna otra referencia. Véase "Marfiles". En El arte en la corte de Nápoles en el siglo XVIII. Madrid, 1990, pp. 279-281. ROMERo Recio, pp. 57-58, figs. 3.1-3.3.

58. Pannuti, Ulrico. Il Giornale degli scavi di Ercolano (1738-1756). Roma, 1983, p. 181. 
que se dibujen y reproduzcan con fines docentes. Aunque aún seguía pendiente la serie prevista sobre la escultura en mármol, sin embargo, entrega también los yesos correspondientes quizá porque ya habían pasado cuarenta años desde el descubrimiento de algunas de esas piezas, como el oscillum de Herculano ${ }^{59}$.

Pero sin tener acceso a los originales, el conocimiento de los bronces a través de los yesos y de la pintura mediante las estampas, resultaba difícil de asimilar para aquellos artistas al servicio de Carlos III que no habían salido de España. Se establece aquí una clara distinción entre los que habían estado en Italia y los que no. El primer grupo estaba formado por italianos que habían llegado acompañando al rey o se habían incorporado poco después y por los españoles que habían tenido la oportunidad de formarse en Roma, viajar hasta Nápoles y conocer otras ciudades. Basta recordar aquí a Jovellanos, a Ventura Rodríguez y a Rejón de Silva que nunca pudieron realizar el giro por tierras italianas pese a sus intereses artísticos. Pero en conjunto no eran tantos los que habían experimentado la confrontación con los originales, lo que unido a la dilación de su publicación explica lo tarde que los llamados motivos pompeyanos se incorporan al repertorio español. El viaje a Nápoles, con la visita al Museo de Portici, no era algo que realizasen todos los pensionados, sin embargo, accederán al conocimiento del mundo clásico desde la Domus Áurea y contemplando la multitud de relieves distribuidos por Roma. Entre ellos los de la Villa Medici donde estaba uno de los roleos de acanto más copiados por todos los estudiosos de la Antigüedad y del que Mengs donará una copia en yeso a la Academia ${ }^{60}$. Las notas, apuntes y bocetos de multitud de modelos clásicos se volcarán en los cuadernos de dibujos que son la herramienta imprescindible que acompaña a los artistas en sus viajes y constituye una alternativa más personal y asequible que la adquisición de estampas, que era otra de las formas de mantener la memoria de lo que se había visto para poder conservarlo como experiencia profesional ${ }^{61}$. Destaca entre ellos el taccuino de Domingo Lois Monteagudo, pensionado en Roma los mismos años que Villanueva y José del Castillo, porque contiene todos los objetos que se estaban demandando en esas fechas: relieves, aras, cipos, trípodes, lucernas, urnas, cráteras, pebeteros, esfinges, capiteles y puteales. Ningún otro pensionado de San Fernando en esa época se interesó tanto por documentar las antigüedades como lo hizo Lois Monteagudo. Pese a ello no parece que el fin de su Libro de los barios adornos sacados de las mejores fábricas de Roma fuese la publicación como proponen algunos autores ${ }^{62}$.

59. Alonso Rodríguez. 2009b, p. 68, fig. 3.

60. Negrete Plano, Almudena. La colección de vaciados de escultura que Antonio Rafael Mengs donó a Carlos III para la Real Academia de Bellas Artes de San Fernando. Madrid, 2012, p. 10.

61. VV. AA. Roma en el bolsillo. Cuadernos de dibujo y aprendizaje artístico en el siglo XVIII. Madrid, 2013

62. Biblioteca Nacional, DIB/18/1/9925 (disponible online). DíEz DEL Corral Corredoira, Pilar. "El "Libro de Barios Adornos" de Domingo A. Lois Monteagudo (1723-1786): formación académica en Roma y el ornamento "all'antica" en el contexto internacional del Setecientos Borbónico". En Dibujo 
Pero mientras el rey no vendía su obra con los grabados herculanenses, la demanda que surge de publicaciones sobre antigüedades es aprovechada por artistas que ven en la estampa una oportunidad de negocio. La posibilidad de comprar ejemplares sueltos, bien como recuerdo de viaje o para su estudio, dispara este tipo de comercio. Piranesi es quizá el más activo, pero a él se suman Giovanni Ottaviani y Giovanni Volpato, entre 1772 y 1777, con la serie de las Logias de Rafael en el Vaticano ${ }^{63}$. Es significativo, al respecto, el comentario de Azara de que «en Madrid no había más copias que las estampas de Volpato, a las que les faltaba el verdadero colorido y sobre todo el verdadero carácter y expresión» ${ }^{64}$. Poco más tarde, en 1776, Ludovico Mirri pone en marcha la edición de las pinturas de las Termas de Tito en las que colaboran el arquitecto Vincenzo Brenna, el pintor Francesco Smugliewitz, el grabador Marco Carloni y el anticuario Giuseppe Carletti. Este último explica que, para hacer las copias de forma escrupulosa, Brenna tuvo que pasarse varios meses en las grutas subterráneas ${ }^{65}$. Volvemos a encontrar el prurito de fidelidad como un compromiso de los autores y del editor y también las estampas iluminadas llevan la misma advertencia de autenticidad con respecto al original ${ }^{66}$. Tanto el infante don Gabriel como el príncipe de Asturias poseían las estampas miniadas de las Estancias de Rafael cuya compra había gestionado Azara $^{67}$. Así que, si bien Le Antichità fue suministradora de motivos decorativos, no es la única fuente para los artistas españoles que trabajan para las distintas residencias campestres de los príncipes de Asturias y después para los reyes en los Reales Sitios. De todas formas hay que tener en cuenta que estas obras eran costosas y destinadas solo a una élite que podía invertir en este tipo de adquisición.

En 1771 Villanueva comienza la construcción de la Casita del Príncipe en El Escorial. Es otro arquitecto joven, de la generación de los príncipes de Asturias, quien tras pasar varios años de formación en Roma es en esta ciudad y en Paestum donde hallará los motivos de su inspiración clásica, pero no en Herculano ni en Pompeya, puesto que, como hemos señalado, no había edificios en superficie que pudiesen servirle de referencia. Cuando realizó su visita a Nápoles en 1764 se estaba excavando en Pompeya la puerta de Herculano, mientras que en Herculano

\footnotetext{
y Ornamento, Trazas y dibujos de artes decorativas entre Portugal, España, Italia, Malta y Grecia. Córdoba, 2015, p. 363.

63. Loggie di Rafaele nel Vaticano. Cai. Savorelli Pict, et Pet. Camporesi Arch. delin.; Joann. Ottaviani sculp. cum privilegio S.S.D.N. Clementis PP. XIII; Ludovicus Teseo Taurinensis delin.; Joannes Volpato sculp. Romae 1775. Roma, 1769-1777.

64. De la Paz Ricardo, Nieves. "José Nicolás de Azara y Perea». En El Westmorland, recuerdos del Grand Tour. Madrid, 2002, p. 219.

65. MirRI, Ludovico y CARLETTI, Giuseppe. Le antiche camere delle Terme di Tito, e le loro pitture ... delineate, incise, depinte, ... e descritte dall'abate Giuseppe Carletti. Roma, 1776.

66. LuZón NoguÉ, Jose M. ${ }^{\mathrm{a}}$. "La captura y venta del Westmorland». En El Westmorland, recuerdos del Grand Tour. Madrid, 2002, pp. 101 y ss. Idem. "Copia de una decoración mural romana", pp. 246-248.
}

67. URREA FERnÁNDEZ, Jesús. Relaciones artísticas hispano-romanas. Madrid, 2006, pp. 120-121. 
se continuaba trabajando en el teatro ${ }^{68}$. Pero si Carlos III entendía la Antigüedad de una manera, son sus hijos los que lo hacen de forma muy distinta al incorporarla a la vida diaria y fundamentalmente a los espacios privados. Tanto los príncipes de Asturias como los artistas de su generación son los que se interesarán más por una reelaboración del mundo clásico que ya venía produciéndose en el resto de Europa, especialmente en Inglaterra y Francia. De igual forma, es Villanueva, con su experiencia romana, el que, a diferencia del barroco clasicista de Sabatini, sabrá dar curso a estas aspiraciones con la construcción de las Casitas del Príncipe del Escorial y del Pardo ${ }^{69}$. El pintor José del Castillo, formado igualmente en Roma, en los mismos años que el arquitecto y con quien había visitado en 1764 el Museo Herculanense, no tendrá, sin embargo, una visión tan clara de las nuevas ideas. Su caso es interesante porque primero se le encomienda la finalización los cartones para los tapices del dormitorio del rey, continuando la serie iniciada por Guillermo Anglois en un lenguaje tardobarroco. Hay otros ejemplos en los que vemos su utilización de motivos clásicos en la ornamentación del Gabinete de la princesa de Asturias para el Palacio del Pardo. Son seis cartones para tapices que representan alegorías de la Pintura, la Arquitectura, la Fama, la Música, la Astronomía y la Aritmética sobre un fondo azul claro, con guirnaldas, roleos, flores y aves de inspiración rococó, hoy en depósito en el Museo de Artes Decorativas ${ }^{70}$. Los niños portadores de emblemas están tomados igualmente de un dibujo atribuido a Udine o del Vago, y nada hay pompeyano en esta serie realizada hacia $1775^{71}$. Aunque Castillo viajó hasta Nápoles con Villanueva y pudo visitar el Museo Herculanense, es evidente que su formación anticuaria procede más bien de sus dos estancias en Roma.

Bajo la dirección de Mengs hará la serie de cartones para el Gabinete del Óvalo del palacio del Escorial, en los que combinará imágenes procedentes de la Villa de Cicerón de Pompeya con escenas tomadas de los relieves de la colección Borghese $^{72}$. En ellos Castillo, además de la orla roja de inspiración pompeyana, pinta un marco delimitando las escenas de un sacrificio y de las Horai Borghese, de Apolo y Casandra y la de Eros con dos delfines, recordando cómo se exponían los frescos en el Museo Herculanense, que tras ser extraídos de las paredes

68. En cuanto a los dibujos que pudo enseñarles La Vega serían los planos de las excavaciones ya que ese era su cometido. Moleón, Pedro. «Perfeccionar la formación en Roma (1746-1764). José de Hermosilla y Juan de Villanueva». En XVI Jornadas de Historia de Llerena, 2015, pp. 221-222.

69. Benito García, Pilar. "Fiebre de seda en los palacios de Carlos IV». En Carlos IV, mecenas y coleccionista. Madrid, 2009, p. 94 .

70. Museo Nacional del Prado, inv. P7347-P7352. LunA, Juan José. El bodegón español en el Prado. De Van der Hamen a Goya. Madrid, 2008, n. ${ }^{\circ}$ 47, pp. 132-133.

71. Dacos, Nicole. La decouverte de la Domus Aurea et la formation des grotesques à la Renaissance. London: Gabinetto disegni e stampe, Uffizi. or. 184, 1969.

72. Sanz De Miguel, Carlos. «El Gabinete del Óvalo de María Luisa de Parma en el Escorial: José del Castillo y sus imágenes inspiradas en la Antigüedad Clásica». Reales Sitios: Revista del Patrimonio Nacional, 2012, n. ${ }^{\circ}$ 192, pp. 28-47. JORDÁN DE URRíES, Javier. "El clasicismo en los discípulos de Mengs». En Anton Raphael Mengs y la Antigüedad. Madrid, 2014, p. 101, fig. 2. 
y enmarcados, eran transformados en cuadros para la colección real ${ }^{73}$. En este caso sí podemos decir que estamos ante modelos pompeyanos, al igual que en las sobrepuertas en las que copia a dos oficiantes, la una portando una pátera y una sítula y la otra un instrumento musical, que no un cetro ${ }^{74}$. En ambos casos los colores utilizados siguen fielmente la descripción que acompaña a cada una de las estampas publicadas en 1757. La guirnalda de flores es, sin embargo, rococó y, entre esta y cada una de las figuras, aparece un marco de junquillo recordándonos su condición de cuadros en el museo de Portici.

De la misma manera que las ideas de Mengs tardaron en materializarse en lo que a la Fábrica de Santa Bárbara se refiere, sucede igual en la Fábrica de Porcelana del Buen Retiro. Hasta muy tarde la línea de producción va a tener un marcado carácter continuista con relación a lo realizado en Capodimonte y será la Fábrica Ferdinandea la primera en abrirse a las nuevas propuestas. El llamado Servicio Herculanense, del que hoy se conservan un plato y dos enfriadores en el Museo Nacional de Artes Decorativas, es un regalo de Estado, además de un obsequio familiar destinado para que Carlos III recordase "aquellas cosas que son tan de mi genio y gusto» ${ }^{75}$. La correspondencia de Ferdinando IV con su padre confirma que, además de contribuir a mejorar las relaciones paternofiliales, el objetivo de la vajilla era conmemorar los descubrimientos realizados desde 1738 y vincular a ambos soberanos a la empresa arqueológica. Para ello se incluía a los dos reyes en biscuit paseando por las excavaciones de Herculano, mientras el padre animaba al hijo para que las prosiguiese ${ }^{76}$.

Su envío a España fue dado a conocer en la Gazzetta Universale y la vajilla se expuso al público el 13 de agosto de 1782 en el Palacio Real de Nápoles. La noticia contribuía a demostrar la calidad alcanzada por la porcelana napolitana tanto en sus logros técnicos como su aportación a la industria de objetos de

73. Para Winckelmann las bailarinas Borghese era una de las obras más bellas de la Antigüedad. Negrete. Op. cit., p. 241. Aymonino, Adriano. "The fortune of the "Borghese Dancers" in eighteenthand early nineteenth-century European art and decoration". En Roma fuori di Roma. L'esportazione dell'arte moderna da Pio VI all'Unità (1775-1780). Roma, 2012, p. 480.

74. No está bien interpretado en el cartón y tapiz lo que lleva esta figura en la mano.

75. "En Primicia (V): plato de porcelana». ad+ Museo Nacional de Artes Decorativas». http:// mnartesdecorativas.blogspot.com.es/2013/06/en-primicia-v-plato-de-porcelana.html (consultado el 30-08-2017). Agradezco a Félix García Diez, responsable de investigación del Museo de Artes Decorativas las facilidades dadas para el estudio de estas piezas. La cita pertenece a una carta de Carlos III a Tanucci, Alonso Rodríguez, M. ${ }^{a}$ del Carmen. "Ecos de Herculano. Aquellas cosas que sabes que son tan de mi genio y gustom. En De Pompeya al Nuevo Mundo: la corona española y la arqueología en el siglo XVIII. Madrid, 2008, p. 238.

76. VenuTI, Domenico. Spiegazione d'un servizio da tavola dipinto e modellato in porcellana nella Real Fabbrica di sua maestà il re delle Sicilie: sopra la serie de' vasi, e pitture esistenti nel Real museo Ercolanese per uso di S. M. C. Nápoles: Real Biblioteca: I-F-451, 1782, p. 86. En la elección del yacimiento por el que pasear no estuvo Venuti muy acertado ya que en ese momento las excavaciones en Herculano eran subterráneas y se prefería excavar en la Civita (Pompeya) o en Gragnano (Estabia). 
lujo ${ }^{77}$. El intendente de la fábrica, Domenico Venuti, poseía una sólida formación anticuaria que le capacitaba para la creación de este y otros conjuntos como el denominado Servizio Etrusco, hecho para el rey de Inglaterra. Era hijo de Marcello Venuti, que había identificado el Teatro de Herculano al inicio de las excavaciones y que cometió el error de publicar, antes que la Academia Herculanense, una obra sobre los descubrimientos arqueológicos hechos en Herculano. En 1782, Domenico Venuti redactó una explicación erudita sobre las características e historia de cada una de las piezas de la vajilla que podemos identificar gracias las inscripciones en letras capitales doradas que llevan. Aparecen en el interior de los recipientes o en el reverso de los platos, citando el origen de los modelos reproducidos y su pertenencia a las colecciones de pinturas o de bronces del museo de Portici.

Para cumplir la función de recordatorio era necesario que en la selección de escenas a representar se diese preferencia a los descubrimientos arqueológicos anteriores a 1759, al igual que se había hecho con los yesos traídos por Paderni a Madrid, hoy en la Academia de Bellas Artes de San Fernando. Sin embargo, como vamos a ver, se incorporarán hallazgos encontrados con posterioridad al regreso a España de Carlos III, convirtiéndose la vajilla un compendio de la actividad arqueológica de ambos reyes. Las imágenes del triclinio de la Villa de Cicerón, que continuaban siendo uno de los descubrimientos de Pompeya de mayor éxito, vuelven a plasmarse en varios platos. De igual manera hay objetos importantes encontrados en las excavaciones, como son los braseros de bronce, los ahena o sítulas, que prestan sus formas a los distintos recipientes, así como sus motivos decorativos, que se convierten en un denominador común para todas las piezas. Las cenefas en relieve de todos los componentes de la vajilla están tomadas de un abenum encontrado el 17 de febrero de 1757 en la masseria di Bisogno en Herculano ${ }^{78}$. La banda decorativa está formada por un roleo de volutas de acanto que alterna elementos vegetales y animales. Este recipiente de bronce era un objeto de lujo y lleva un sello con el nombre de su propietaria en genitivo: Corneliae Chelidonis. Existe un dibujo con destino a la edición regia de Giovanni Casanova, grabado por Carmine Pignataro, que no llegó a publicarse, como muchos otros hallazgos, pasando a formar parte de los llamados Rami inediti ${ }^{79}$ (Fig. 3a). Se dará a conocer al público en 1824 en el Real Museo Borbonico atribuyéndose por error el lugar de hallazgo a Pompeya ${ }^{80}$.

77. KnIGHT, Carlo. Il regno di Napoli da la tutela a la emancipazione (1775-1789). Nápoles, 2015, pp. 459-460, n. 21.

78. Museo Arqueológico Nacional de Nápoles, inv. 68854. RugGIERO, Michele. Storia degli scavi di Ercolano ricomposta su' documenti superstiti. Nápoles, 1885, p. 217.

79. Con la forma del ahenum de Cecilia Chelidon se hicieron los dos enfriadores grandes y los dos pequeño de la vajilla. VenuTI, pp 8-9 y 69-77. Grabado reproducido en PAgANO y PRISCIANDARO, vol. II, p. 348, n. ${ }^{\circ}$ 150. Sobre los Rami Inediti véase Esposito, Maria Rossaria. "Rami Inediti». En Carlo di Borbone e la diffusione delle antichità. Nápoles, 2016, pp. 162-167.

80. Los dibujos y grabados del siglo XVIII y XIX presentan algunas variaciones en relación a su estado actual, pero no afectan ni a la identificación del objeto ni a la banda de roleos que nos interesa. 

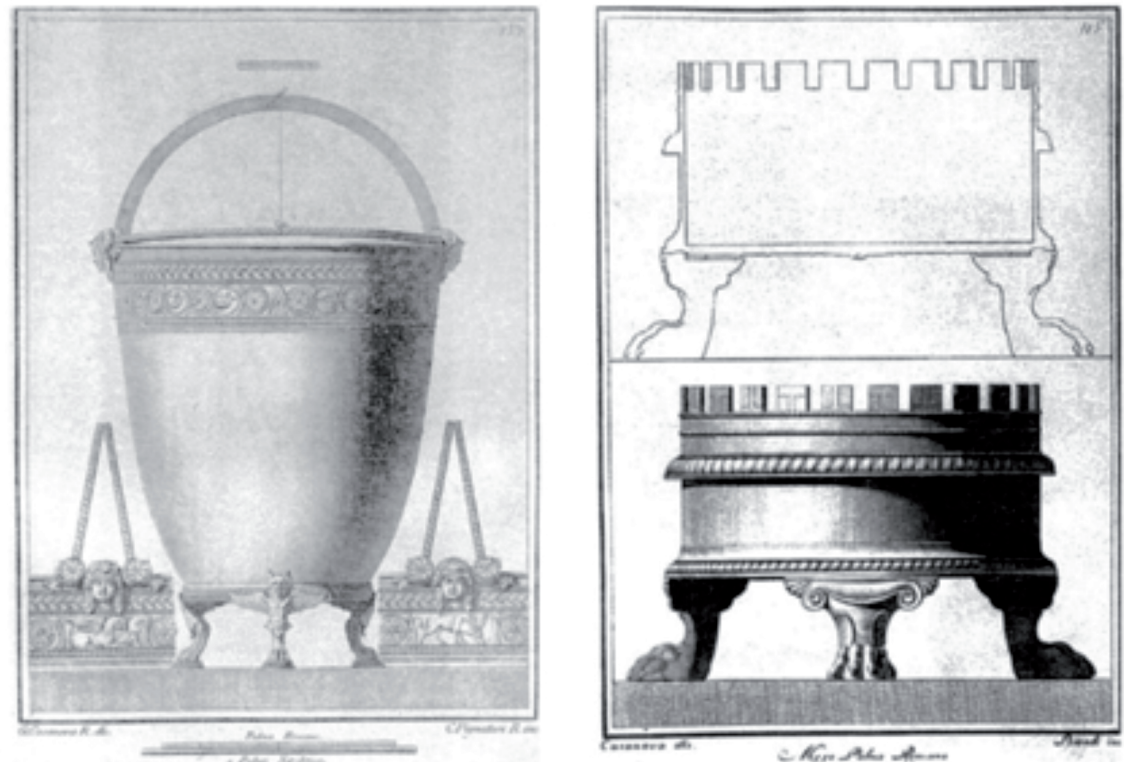

Fig. 3. A: Abenum de Herculano. B: Brasero de Pompeya.

De las tres piezas del Servizio Ercolanese que conserva el Museo Nacional de Artes decorativas, el plato tiene como motivo central un fauno danzante con la cabeza coronada de hedera y cubierto parcialmente por una piel de cabra (Fig. $4)^{81}$. Lleva un khantaros en la mano derecha y un pedum en la izquierda. La orla en relieve que recorre el borde está tomada del ahenum de Cornelia Chelidon y se alterna con cuatro metopas doradas compuestas por aves posadas en ramas y elementos vegetales, tomadas también de Le Antichità. En la parte posterior la inscripción en letras capitales doradas, «MVS. ERCOL. / SERIE DI PITTVRE / VN FAUNO / RITTROVATO NEGLI SCAVI DI CIVITA», nos remite al n. ${ }^{\circ} 12$ de la explicación de Domenico Venuti ${ }^{82}$. El fresco con la representación del fauno apareció en mayo de 1761 en la Casa de Cipius Pamphilus (ínsula VII, 6, 28) de Pompeya publicándose en el volumen IV de las Pinturas de Herculano ${ }^{83}$. A diferencia de la pintura original

Puede deberse a restauraciones antiguas rectificadas con posterioridad. Avellino, Francesco Maria. "Vaso di bronzo rinvenuto a Pompei». En Reale Museo Borbonico. Nápoles, 1825, vol. II, lám. XIV. La ilustración está firmada por otros autores aunque copia la del XVIII.

81. Inv. 27477. http://mnartesdecorativas.blogspot.com.es/2013/06/en-primicia-v-plato-de-porcelana.html (consultado el 30-08-2017).

82. VENUTI, p. 29, n. ${ }^{\circ} 12$.

83. AdE, IV, 1765, lám. XLIVIII. FIORelli, Giuseppe. Pompeianarum Antiquitatum Historia, Addenda. Nápoles, 1860, p. 143. 
y del grabado, la figura representada en el plato levanta un poco más la pierna derecha para ocultar sus atributos masculinos. La Gazzeta Universale estimaba que el precio de cada plato era de más de 40 ducados $^{84}$.

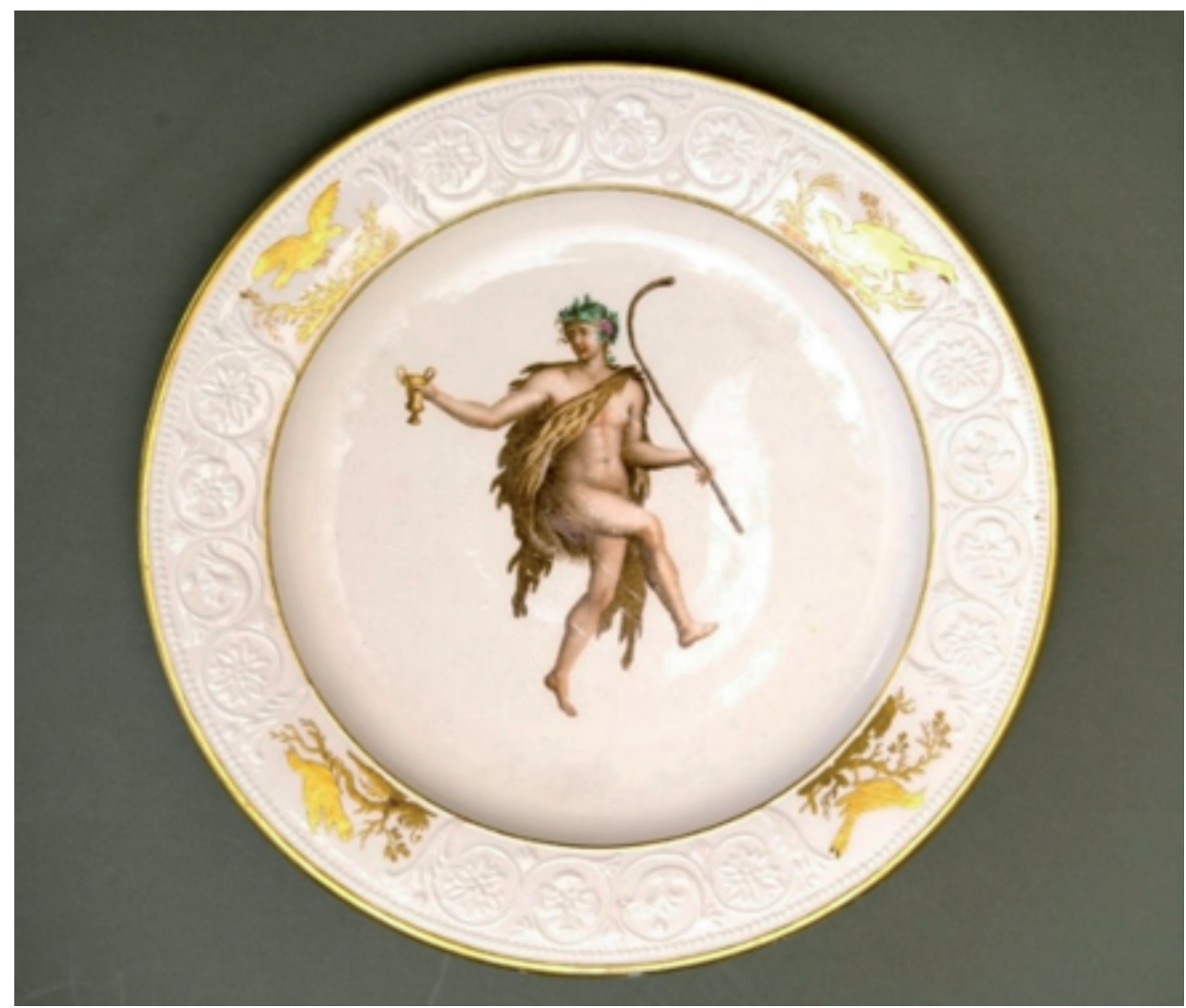

Fig. 4. Plato de la Vajilla Herculanense. 1781-1782. MNAD, CE27477.

Los dos enfriadores del Museo Nacional de Artes Decorativas, denominados cada uno de ellos Sciacqua Bicchiere por Venuti (Fig. 5), imitan paradójicamente un brasero de bronce de forma cilíndrica y borde almenado que va sostenido por tres garras de león ${ }^{85}$. En el momento de su hallazgo, quizá por las cenizas que contenía, se interpretó como un ara y así se le menciona en todas

84. KNIGHT. 2015, 460, n. 21.

85. VENUTI, pp. 10-14, n. ${ }^{\circ}$ 1-2. Inv. 26812/1 y 26812/2. http://mnartesdecorativas.blogspot.com. es/2013/06/en-primicia-v-plato-de-porcelana.html (consultado el 30-08-2017). 
las descripciones y diarios de excavación. En estos dos recipientes del Servizio Ercolanese aparece nuevamente la banda de roleos de acanto en relieve que encontramos en el resto de las piezas y se le añaden dos prótomos de león a modo de asas. La decoración del cuerpo está tomada de un fresco encontrado en Pompeya en una domus atribuida a Gaivs Ivlivs Hephaistos (ínsula VII, 6, 28) la semana del 3 al 7 de abril de $1762^{86}$. Representa una escena de sacrificio dionisiaco desarrollada en el friso de la parte alta de las paredes de tercer estilo pompeyano del cubículo 8.

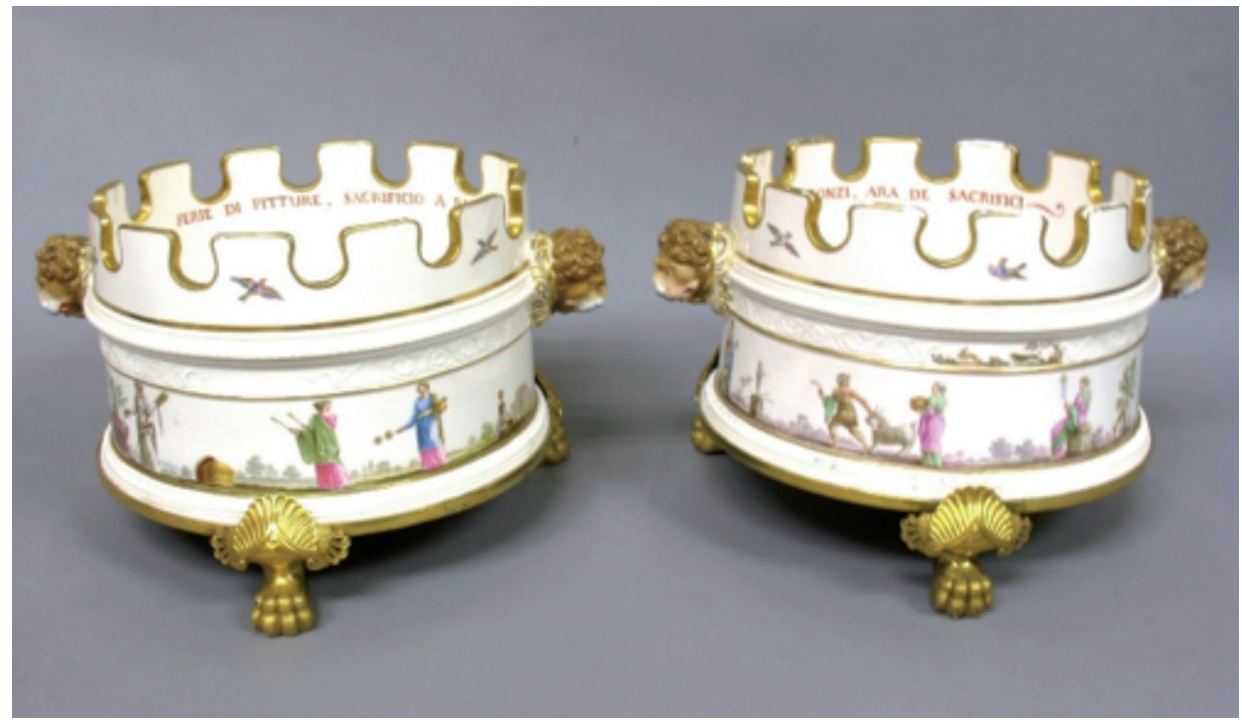

Fig. 5. Pareja de enfriadores de la Vajilla Herculanense. 1781-1782. MNAD, inv. CE26812-1 y CE26812-2.

A estas pinturas Le Antichità di Ercolano le dedicó tres disertaciones y una detallada descripción que Venuti recoge fielmente en su explicación ${ }^{87}$ (Fig. 6).

86. Fioreli. Op. cit., pp. 143-144. SAMPaOlO, Valeria. "Insula VII». En Pompei, Pitture e Mosaici, Regio VII, Parte II. Roma, 1998, vol. VII, pp. 190-192.

87. AdE, IV, 1765, lám. XLVI-XLVII. Bragantini y Sampaolo. Op. cit., pp. 250-251, n. ${ }^{\text {os } 99-100 .}$ 


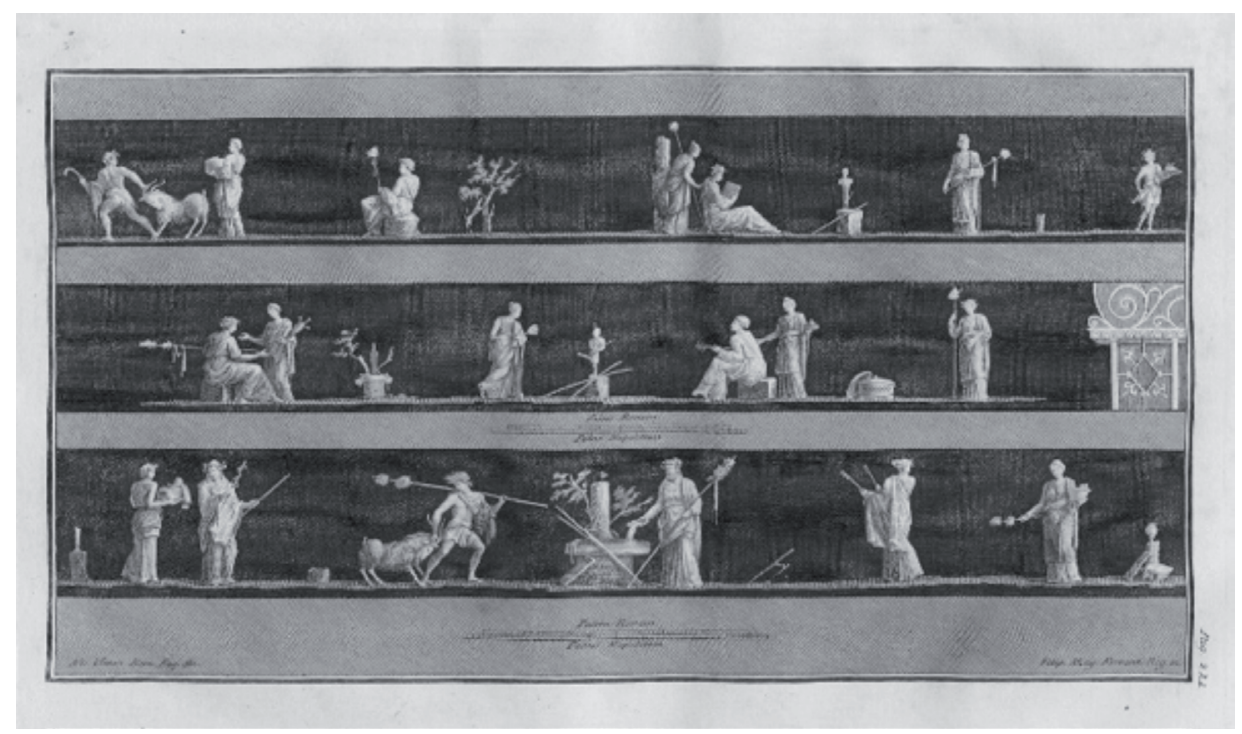

Fig. 6. Sacrificio dionisiaco. Le Antichità di Ercolano IV. 1765.

Por razones de tipo compositivo, el original pompeyano es distribuido en tres bandas horizontales para su edición, por el mismo motivo y con total exactitud se reparten entre los dos enfriadores a razón de banda y media cada uno. Las escenas representadas están compuestas por parejas femeninas que participan en un sacrificio dionisiaco, portando tirsos, instrumentos y distintas ofrendas. Los personajes masculinos actúan como victimarius y de oficiante respectivamente. Los ritos tienen lugar al aire libre, donde las aras, los árboles sagrados y las hermas son los escasos elementos de referencia a un santuario al aire libre. Estos dos enfriadores de porcelana descansan sobre un plato de bronce dorado con tres patas con forma de garra de león rematadas por palmetas. En el interior, en letras capitales doradas leemos la inscripción MVS. ERCOL. SERIE DE BRONZI. ARA DE SACRIFICJ. SERIE DI PITTVRE. / SACRIFICIO A BACCO. Se hace con ello mención tanto al recipiente de bronce como a las pinturas del Museo Herculanense. El brasero apareció en Pompeya en la llamada Casa de Salustio (ínsula VI, 2, 4) el 8 de junio de 1781. Existe de él un grabado de Carlo Nolli dibujado por Giovanni Casanova que está recogido en los citados Rami Inediti (Fig. 3b) ${ }^{88}$. La elección de la escena del sacrificio viene condicionada por lo que se había interpretado como un ara

88. Pagano y Prisciandaro. Op. cit., p. 340, n. ${ }^{\circ}$ 87. Museo Arqueológico Nacional de Nápoles inv. 73997. 
y muestra la habilidad de Venuti para organizar los programas decorativos de las producciones de la fábrica napolitana.

Mas interesantes si cabe son los bustos en biscuit diseñados como elementos decorativos del dessert de la vajilla. Ferdinando IV le escribe al padre que los bustos seleccionados son aquellos que tan bien conocía, en una clara referencia a los yesos hechos a partir de los originales encontrados en la Villa de los Papiros y que se enviaron a Madrid en $1765^{89}$. Los bustos que menciona Venuti coinciden con los que se habían mandado a Carlos III ${ }^{90}$. Alvar González Palacios publica un busto de Séneca del museo de Capodimonte y otro de un sacerdote de Isis de Florencia que pone en relación con tres ejemplares de la Colección Laiglesia que se conservan en Madrid, en el Museo de Historia de la Ciudad y que tradicionalmente se han atribuido a Buen Retiro ${ }^{91}$. Cuando se disponga de análisis suficientes con espectrografía Rahman, que permitan diferenciar ambas producciones, sobre todo para las series de bustos de pasta dura, como ya se ha hecho con algunos ejemplos de Buen Retiro y Capodimonte, se podrá establecer a qué manufactura pertenecen los tres ejemplares madrileños ${ }^{22}$. Además de estos bustos, en ambas fábricas existen otras series de esculturas de menor tamaño del Museo Herculanense, especialmente de la Villa de los Papiros y de la colección Farnese que tienen sus paralelos en Buen Retiro ${ }^{93}$. Esta manufactura contaba para ello con vaciados de yeso de los originales reproducidos en pasta dura que se trasladaron a la Academia de San Fernando en 1811, poco antes de ser destruida ${ }^{94}$. Las múltiples referencias a la frialdad con la que Carlos III acogió el regalo de su

89. Nápoles, 6 de septiembre de 1782. Knight. Op. cit., p. 480, n. . 39. Alonso RodríGuez. 2010, op. cit., pp. 243-244. En esa publicación incluimos erróneamente un busto de Dionisos Platón de la Real Biblioteca con los modelos de terracota utilizados para la realización del dessert de la Vajilla Herculanense, relacionándolos con los realizados Celebrano. Veáse GonZÁlEz PALACIOS. Ibid., pp. 175-176. Giusti, Paola. "La Real Fábrica de Porcelana de Nápoles». En El arte en la corte de Nápoles en el siglo XVIII. Madrid, 1990, p. 170. Herrero SANZ, M. ${ }^{a}$ Jesús. "Las antigüedades de Herculano y su impacto en las colecciones reales». Reales Sitios: Revista del Patrimonio Nacional, 2003, 40, n. ${ }^{\circ}$ 156, p. 52.

90. Venuti, p. 88. Enumera doce bustos: Séneca, Escipión, Palas, Júpiter Amón, Arquímedes, Silla, Berenice, Marco C. Marcello, Cayo César, Tolomeo Soter y dos más de personajes desconocidos.

91. Catálogo de la colección de porcelanas del Buen Retiro del Excmo. señor D. Francisco de Laiglesia. Madrid, 1908, pp. 31 y ss., lám. XII. GonZÁlez Palacios, Ibid., p. 175.

92. Ricciardi, Paola; Colomban, Philippe y Milande, Veronique. "Non-destructive Raman characterization of Capodimonte and Buen Retiro porcelain». Journal of Raman Spectroscopy, 2008, n. ${ }^{\circ}$ 39, pp. 1113-1119. Fabbri, Bruno; Ricciardi, Paola y Colomban, Philippe. "The Study of the Capodimonte Production: an Occasion for the Proposal of a Raman Database for Ancient Porcelains". En 9th International Conference on NDT of Art. Jerusalén, 25-30 May 2008. www.ndt.net/search/docs. php3?MainSource=65 (consultado el 17/08/2017).

93. "Quattordici maezzi busti" atribuidos a Tagiolini. CARÒla PERrotTI, Angela. La Porcellane dei Borbone di Napoli, Capodimonte e Real Fabbrica Ferdinandea (1743-1806). Nápoles, 1986. MAÑUECO Santurtun, Carmen. Manufactura del Buen Retiro 1760-1808. Madrid, 1998, pp. 507-509.

94. Archivo-Biblioteca RABASF, sig. 3-616, fols. 41r.-42r. Inventario de las alhajas y muebles existentes en la Real Academia de San Fernando de 1804. Hay copia digital y transcripción disponibles online. 
hijo y a sus portadores, Giacomo Milani y Antonio Cioffi, contribuyen a explicar de alguna manera la disgregación de este conjunto y la ausencia de ejemplares en las Colecciones Reales. Los distintos componentes del Servizio Ercolanese, llegado a Madrid en el siglo XVIII, se hallan en la actualidad dispersos entre distintos museos y colecciones privadas, pero, con cierta regularidad, aparecen en el mercado y salen a subasta algunas piezas atribuidas a la original o a sus posibles copias ${ }^{95}$.

Volveremos a encontrarnos con las figuras de los frescos del triclinio de la Villa de Cicerón en los denominados cartones pompeyanos de los hermanos Agustín y Juan Navarro, que realizan entre 1787 y 1788 bajo la dirección de Maella ${ }^{96}$. La serie la inicia Agustín, formado en Roma donde tuvo la oportunidad de conocer bien las Logias de Rafael cuando realizó una copia del Incendio del Borgo ${ }^{97}$. Los cartones pompeyanos reproducen figuras femeninas de la mencionada villa flotando sobre un fondo que simula lapislázuli, pero insertas en marcos octogonales al estilo de la Domus Áurea. Su autor declaraba que la mayoría de los motivos empleados eran de las "Lochas de Rafael»" ${ }^{8}$. Por ejemplo, la imagen principal del cartón del Invierno está tomada de la Domus Áurea y reproducida por Volpato, al igual que la pequeña escena de caza del jabalí a la manera de un pinax. Vemos, por lo tanto, en multitud de casos, cómo la referencia romana era más accesible a los pintores y, por lo tanto, se empleaba con mayor frecuencia que el corpus herculanense. El mismo caso se da en las bóvedas y techos de la Casita del Príncipe del Pardo, donde Vicente Gómez recurre a los grutescos para el Salón Rojo y a la Domus Áurea para el techo del Gabinete de la Reina. Javier Jordán de Urríes, al identificarlos, señala que en 1796 la viuda de Gómez vende a Carlos IV un libro de las Logias de Rafael de la edición de Ottaviani y Volpato usada por su marido ${ }^{99}$. Recurriendo a la versión difundida por Mirri, Manuel Pérez copia para la Sala del Barquillo las Bodas Aldobrandinas. Otras estampas presentes en la edición de las pinturas de la Termas de Tito se adaptarán también con éxito a las alfombras ${ }^{100}$.

95. GonzÁlez PALACios, Alvar. "La Vajilla Ercolanese de Carlos III". En El arte en la corte de Nápoles en el siglo XVIII. Madrid, 1990, p. 195, figs. 36 a y 36 b. Hay una discordancia entre el texto y las figuras de los platos.

96. Agradezco a Marian Granados, conservadora jefe del Departamento de Edad Moderna del Museo Arqueológico Nacional, la información facilitada sobre las características de esta serie de cartones. Museo Arqueológico Nacional: 1941/85/5, 1941/85/5. Véanse las dos fichas de catalogación en la Red Digital de Colecciones de Museos de España (CERES). SAnCho Gaspar, José Luis. El Palacio de Carlos III en el Pardo. Madrid, 2002, pp. 252-253.

97. URrEa, pp. 224-225.

98. Ceballos Escalera, Isabel. "Lienzos decorativos de estilo pompeyano». En Adquisiciones del Museo Arqueológico Nacional (1940-1945). Madrid, 1947, pp. 203-204.

99. JoRDÁn DE URRíES, Javier. "El gusto de Carlos IV en sus casas de campo». En Carlos IV, mecenas y coleccionista. Madrid, 2009, pp. 64 y ss.

100. La de Pedro Cancio para Aranjuez mientras que otra de Juan Bautista Stuyck se inspira en las Logias de Rafael. Benito García, Pilar. "Alfombra del antiguo sitial de la Capilla Real de Aranjuez". Ibid., pp. 194-195, n. ${ }^{\circ}$ 49. SANCHO, José Luis. "Tapete de la mesa de despacho de Carlos IV". Ibid., pp. 309-310. 
Aunque no sabemos qué papel jugarían en el repertorio colectivo de los artistas españoles los grutescos de los frescos de la bóveda de la Sala de las Batallas del Monasterio del Escorial, inspirados en Pierino del Vaga.

Muchos de los elementos pertenecientes al léxico pompeyano reinterpretados como ejemplos aislados se traducen en distintos contextos. Algunos, como hemos visto en los cartones de Castillo que están en el Museo de Artes Decorativas, se expresan con un lenguaje más próximo al rococó que a la visión del mundo clásico propagada por Mengs y Winckelmann. En las banquetas del Salón de Baile de la Casa del Labrador encontramos el eco de las sillas curules del Teatro de Herculano, pero la versión creada por Isidro González Velázquez combina ya el modelo herculanense con dos cabezas de esfinges de clara inspiración egiptizante ${ }^{101}$. Unos años antes, en 1786, Jean-Démosthène Dugourc había diseñado una sala egipcia, además de otra etrusca para la Casa del Príncipe del Pardo que, aunque no llegaron a realizarse, dan fe de la existencia de otros intereses anticuarios que estaban ya sólidamente instalados en Europa ${ }^{102}$. En la reelaboración de los nuevos repertorios se incluyen modelos tomados de la cerámica suritálica, conocida entonces como «etrusca». Carlos IV se interesó asimismo por la adquisición de esta clase de vasos, recibiendo en 1791 cincuenta ejemplares regalados por Domenico Venuti ${ }^{103}$. A través de la cerámica griega se difunden modelos que tendrán gran aceptación a final de siglo, como son el klismos, difros, kline y el trípode. En sus versiones griega o romana va a ser Piranesi quien contribuya a la difusión de este último con sus estampas dedicadas a los viajeros del Grand Tour y a los clientes distinguidos que adquirían sus obras ${ }^{104}$. Muchos de estos personajes, pertenecientes a las élites económicas británicas, se llevarán también consigo, de regreso a su país, el deseo de recrear ambientes romanos. En ese caso será la aristocracia, a diferencia de España, la que adoptará dichos modelos en fechas más tempranas que el resto del continente. Robert Adam visita el museo de Portici en 1755 y de vuelta a Inglaterra es quien crea los primeros espacios de gusto pompeyano en Syon House, Kenwood House y Saltram House ${ }^{105}$. James Stuart viajó a Nápoles en 1749, cuando el Museo Herculanense aún no existía y acababan de descubrirse las pinturas de la Villa de Cicerón. De Nápoles siguió viaje a Grecia y de allí

101. JORDÁN DE URRÍES, Javier. "Banqueta». Ibid., pp. 316-317, n. ${ }^{\circ} 131$.

102. SANCHO, José Luis y JoRDÁn DE URRíEs, Javier. "Alzado de uno de los testeros de una galería etrusca para la casa de campo del príncipe del Escorial». Ibid., pp. 210-211. SANCHO, José Luis. "Cuatro diseños para la decoración de la Casita del Pardo». Ibid., pp. 211-213.

103. Los primeros vasos suritálicos llegaron a Madrid en 1739 como regalo de Michel Reggio a Isabel de Farnesio. Alonso RodríGuez, M. ${ }^{a}$ del Carmen. "Los vasos griegos en las colecciones reales españolas». En El vaso griego y sus destinos. Madrid, 2004, pp. 315-317.

104. A bordo del Westmorland venían dos estampas de estos trípodes de Piranesi dedicadas a dos de los viajeros ingleses. SÁncheZ-JÁuregui, M. ${ }^{a}$ Dolores. "Trípode, ovvero ara antica di Marmo"; "Altra Veduta dello stesso Tripode antico di Marmo". En El Westmorland, pp. 303-305.

105. Aymonino, Adriano. "Syon House e la fortuna delle fonti antiquarie nella decorazione inglese del Settecentom. En Roma e I'Antico. Realtà e visione nel 700. Roma, 2010, pp. 208 y ss. 
vendrá la inspiración para el trípode de la Wentworth Woodhouse ${ }^{106}$. De hecho, Stuart, primero en la Spencer House y más tarde en la Dressing Room de Osterley Park (1773-74), inicia lo que conocemos como Pompeian-cum-Etruscan ${ }^{107}$. Esto es, crea un repertorio híbrido formado por motivos procedentes de la Domus Aurea, de las pinturas de Herculano y de los vasos griegos. Es la misma combinación, en sus diversas versiones, que vamos a encontrar en el Salón de Baile de la Casa del Labrador o en el Gabinete de Platino, esta vez en una versión a cargo de adornistas franceses ${ }^{108}$. En el Salón de Baile los sátiros de la Casa de Cicerón son transformados de frescos romanos en figuras al estilo de la cerámica suritálica, con pequeñas variaciones que afectan a las posturas y cambios en los instrumentos que tocan. Pero de todas las combinaciones posibles, es la Saleta de la Reina en la Casita del del Pardo la que sin parecerse a ninguno de los ejemplos conocidos hasta ese momento es, sin embargo, la que transmite una atmósfera más próxima a un interior romano. Su paralelo más cercano está en las arquitecturas dibujadas por Piranesi del Teatro de Herculano o por Brenna para las Termas de Tito, donde comparten la escenografía teatral tripartita, los paños colgantes a manera de guirnaldas, los zócalos alineados con entrantes y salientes inspirados en la escena del teatro, la colocación de estatuas sobre pedestales, la proporción entre las figuras y la arquitectura y la perspectiva de los elementos de cubrición de la escena ${ }^{109}$.

Por medio de los tapices, las sedas bordadas, las alfombras y los muebles será posible imitar los interiores de las domus, estuviesen en Roma o en el entorno del Vesubio, sin pretender alcanzar una exactitud filológica. En ellas los frescos con pinturas del tercer y cuarto estilo cubrían la totalidad de las paredes de las principales áreas domésticas, simulando zócalos, cornisas y bóvedas pobladas con guirnaldas y roleos, cuadros o pinakes y también simulando arquitecturas efímeras. La decoración de las distintas Casas de Campo del Escorial, el Pardo y Aranjuez permitía evocar, de alguna manera, a sus propietarios el interior de esas villas suburbanas dedicadas al ocio y al descanso. En palabras de Jesusa Vega, era fácil experimentar la ilusión de vivir en primera persona la Antigüedad ${ }^{110}$. Pero su adopción fue un proceso lento del que apenas participó Carlos III, pese a haber sido el monarca que había propiciado y sostenido los descubrimientos de Herculano, Pompeya y Estabia. Su objetivo fue, como decían sus contemporáneos, el de restaurar la Antigüedad, mientras que el deseo de Carlos IV y María Luisa era vivirla, sin ninguna preferencia concreta en cuanto a su origen, fuese

106. Victoria \& Albert, inv. M.46-1948.

107. Amery, Colin y Curran, Brian. The Lost World of Pompei. Los Ángeles, 2002, p. 170.

108. JoRdán DE URRíES, Javier y SANCHO, José Luis. "Gabinete de Platino de la Real Casa del Labrador en Aranjuez". En Charles Percier e Pierre Fontaine dal soggiorno romano alla trasformazione di Parigi. Milán: Studi Biblioteca Hertziana 9, 2014, pp. 133-143.

109. Piranesi. Lám. VII, figs. I-II; Mirri, estampa n. ${ }^{\circ} 21$.

110. VEGA, Jesusa. "Interrelaciones entre técnica y realidad en el arte de la corte borbónica: la Antichità de Ercolano esposte». Ars Longa: Cuadernos de Arte, 2016, n. ${ }^{\circ}$ 25, p. 178. 
este romano, pompeyano, etrusco o egipcio. Pero esa evocación del pasado, tal y como la concebían Winckelmann y Mengs, se queda en el aspecto meramente formal y el mundo antiguo sobrevivirá en los entornos cortesanos desprovisto ya de cualquier significado.

\section{BIBLIOGRAFÍA}

Allroggen Bedel, Agnes. "L'Antico e la politica culturale dei Borbone». En Herculanense Museum. Laboratorio sull'antico nella Reggia di Portici. Nápoles, 2008.

Alonso Rodríguez, M. ${ }^{a}$ del Carmen. «La colección de Antigüedades comprada por Camillo Paderni en Roma para Carlos III». En Illuminismo e ilustración: le antichità e i loro protagonisti in Spagna e in Italia nel XVIII secolo. Roma, 2003.

Alonso Rodríguez, M. ${ }^{a}$ del Carmen. "Vaciados del siglo XVIII de la Villa de los Papiros de Herculano en la Real Academia de Bellas Artes de San Fernandon. Boletín de la Real Academia de Bellas Artes de San Fernando, 100-101 (2005). Madrid, 2007.

Alonso Rodríguez, M. ${ }^{a}$ del Carmen. "Ecos de Herculano: Aquellas cosas que sabes que son tan de mi genio y gusto». En Corona y Arqueología en el siglo de la Luces. Madrid, 2010.

Alonso Rodríguez, M. ${ }^{a}$ del Carmen. "Las excavaciones de Herculano, Pompeya y Estabia en el siglo XVIII: cómo y dónde excavar». En Pompeya. Catástrofe bajo el Vesubio. Madrid, 2012.

Alonso Rodríguez, M. ${ }^{a}$ del Carmen. "La Política cultural de las Dos Sicilias y la publicación de los descubrimientos arqueológicos». Revista de Historiografía, 2012, n. ${ }^{\circ}$ 17, IX, 2.

Alonso Rodríguez, M. ${ }^{a}$ del Carmen. "La empresa anticuaria de Carlos III entre Nápoles y Madrid». En Política exterior y científica de un reinado ilustrado. Madrid, 2016.

Amery, Colin; Curran, Brian. The Lost World of Pompei. Los Ángeles, 2002.

Avellino, Francesco Maria. "Vaso di bronzo rinvenuto a Pompei». En Real Museo Borbonico, vol. I, Roma, 1838.

AYMONINO, Adriano. «Syon House e la fortuna delle fonti antiquarie nella decorazione inglese del Settecentom. En Roma e I'Antico. Realtà e visione nel 700. Roma, 2010.

AYMonino, Adriano. "The fortune of the "Borghese Dancers" in eighteenth- and early nineteenth-century European art and decoration". En Roma fuori di Roma. L'esportazione dell'arte moderna da Pio VI all'Unità (1775-1780). Roma, 2012.

Benito García, Pilar. "Fiebre de seda en los palacios de Carlos IV». En Carlos IV, mecenas $y$ coleccionista. Madrid, 2009.

Bologna, Ferdinando. «La Riscoperta di Ercolano e Pompei nella cultura artistica del settecento europeo». En Rediscovering Pompei. Roma, 1990.

CARLos III. Cartas a Tanucci. Introducción, transcripción y notas Maximiliano Barrio. Madrid, 1988.

CARÒla PerrotTi, Angela. Le Porcellane dei Borbone di Napoli, Capodimonte e Real Fabbrica Ferdinandea (1743-1806). Nápoles, 1986.

D'Alconzo, Paola. L'Anello del Re. Florencia, 1993.

D'Alconzo, Paola. "Carlo di Borbone a Nápoli: passione archeologiche e immagine della monarchia». En Cerimoniale dei Borbone di Napoli, 1734-1801. Nápoles.

Dacos, Nicole. La decouverte de la Domus Aurea et la formation des grotesques à la Renaissance. Londres, 1969. 
Díez del Corral Corredoira, Pilar. "El "Libro de Barios Adornos" de Domingo A. Lois Monteagudo (1723-1786): formación académica en Roma y el ornamento "all'antica" en el contexto internacional del Setecientos Borbónico». En Dibujo y Ornamento, Trazas y dibujos de artes decorativas entre Portugal, España, Italia, Malta y Grecia. Córdoba, 2015.

Diodati, Luigi. Vita dell'abate Ferdinando Galiani. Nápoles, 1788.

D'Iorio, Aniello. "La Stamperia reale dei Borbone di Napoli: origine e consolidamento". Editoria e cultura a Napoli nel XVIII secolo. Nápoles, 1998.

Esposito, Maria Rossaria. "Rami Inediti». En Carlo di Borbone e la diffusione delle antichità. Nápoles, 2016.

Estella Marcos, Margarita. "La Casita del Príncipe del Escorial. Sala de los Marfiles». Reales Sitios, 1978, 15 (57).

FABBri, Bruno; Ricciardi, Paola y Colomban, Philippe. «The Study of the Capodimonte Production: an Occasion for the Proposal of a Raman Database for Ancient Porcelains». En 9th International Conference on NDT of Art. Jerusalén, 25-30 May 2008. www.ndt. net/search/docs.php3?MainSource=65 (consultado el 17/08/2017).

FERnÁn NúÑEZ, Conde de. Vida de Carlos III, t. II. Madrid, 1898.

Fernández Murga, Félix. Carlos III y el descubrimiento de Herculano, Pompeya y Estabia. Salamanca, 1989.

FIORELl, Giuseppe. Pompeianarum Antiquitatum Historia, vol. I. Nápoles, 1860.

García Fernández, M. ${ }^{a}$ Soledad. "Trono de Carlos III». En Carlos III, Majestad y Ornato en los escenarios del Rey Ilustrado. Madrid, 2016.

Giusti, Paola. «La Real Fábrica de Porcelana de Nápoles». En El arte en la corte de Nápoles en el siglo XVIII. Madrid, 1990.

GonZÁlez Palacios, Alvar. «La Vajilla Ercolanese de Carlos III». El arte en la corte de Nápoles en el siglo XVIII. Madrid, 1990.

Granados Ortega, Marian. "Las porcelanas de la Real Fábrica de Su Majestad Católica». En Carlos III, Majestad y Ornato en los escenarios del Rey Ilustrado. Madrid, 2016.

GRELL, Chantal y Michel, Christian. "Érudits, hommes de lettres et artistes en France au XVIII ${ }^{e}$ siècle face aux découvertes d'Herculanum». En Ercolano 1738-1988: 250 anni di ricerca archeologica. Nápoles.

Herrero SANZ, María Jesús. «Las antigüedades de Herculano y su impacto en las colecciones reales». Reales Sitios: Revista del Patrimonio Nacional, 2003, 40, n. ${ }^{\circ} 156$.

Herrero SANZ, María Jesús. «El Desengaño”. En Carlos IV mecenas y coleccionista. Madrid, 2009.

JoRDÁN DE URRíES y DE LA COLINA, Javier. «La embajada de José Nicolás de Azara y la difusión del gusto neoclásico». En Roma y España un crisol de la cultura europea en la Edad Moderna. Madrid, 2007.

JoRDÁN DE URRíES y DE LA COLINA, Javier. «El clasicismo en los discípulos de Mengs». En Anton Raphael Mengs y la Antigüedad. Madrid, 2014.

Jordán DE URRíES y DE la COLINA, Javier y SANCHO GASPAR, José Luis. «Gabinete de Platino de la Real Casa del Labrador en Aranjuez". En Charles Percier e Pierre Fontaine dal soggiorno romano alla trasformazione di Parigi, Studi Biblioteca Hertziana 9. Milán, 2014.

Knight, Carlo. Carteggio San Nicandro-Carlo III, Il periodo della Reggenza (1760-1767). Nápoles, 2009. 
KNIGHT, Carlo. Il regno di Napoli dalla tutela all'emancipazione (1775-1789). Nápoles, 2015.

LuZÓn Nogué, José M. ${ }^{\text {. }}$ "Germánico». En Esculturas de Velázquez para el Alcázar. Madrid, 2007.

MANSI, Maria Gabriella. "Libri del Re. Le antichità di Ercolano esposte». En Herculanense Museum. Laboratorio sull'antico nella Reggia di Portici. Nápoles, 2008.

MaÑueCo Santurtún, Carmen. Manufactura del Buen Retiro 1760-1808. Madrid, 1998.

MARTINI, Vega de. "Le reproduzioni dell'antichità: i gessi di Carlo e i biscuit di Ferdinando di Borbone». Boletín de la Real Academia de Bellas Artes de San Fernando 100-101 (2005)

Moleón Gavilanes, Pedro. "La difusión de la imagen de Paestum en el siglo XVIII. De Pompeya al Nuevo Mundo: la corona española y la arqueología en el siglo XVIII. Madrid, 2008.

Moleón Gavilanes, Pedro. "Perfeccionar la formación en Roma (1746-1764)». En José de Hermosilla y Juan de Villanuevam. XVI Jornadas de Historia de Llerena, 2015.

Moorman, Eric M. Pompeii's Ashes: The Reception of the Cities Buried by Vesuvius in Literature, Music, and Drama. Berlín, 2015.

Negrete Plano, Almudena. La colección de vaciados de escultura que Antonio Rafael Mengs donó a Carlos III para la Real Academia de Bellas Artes de San Fernando. Madrid, EPrints UCM. Id: 17146, 2012.

Pagano, Mario y PRISCIANDARO, Raffaele. Studio sulle provenienze degli oggetti rinvenuti negli scavi borbonici del Regno di Napoli. Nápoles, 2006.

PANNuTTI, Ulrico. Il Giornale degli scavi di Ercolano (1738-1756). Roma, 1983.

PAZ RICARDO, Nieves de la. "José Nicolás de Azara y Perea». En El Westmorland, recuerdos del Grand Tour. Madrid, 2002.

PIRANESI, Francesco. Il Teatro di Ercolano. Roma, 1783.

PONZ, Antonio. Viaje de España, vol. VI. Madrid, 1782.

PRAz, Mario. Gusto neoclásico. Barcelona, 1982.

RAPISARDA, Stefano. "Notizia biográfica», d'Épinay, Luise, Galiani, Ferdinando. Epistolario 1769-1772. Palermo, 1996.

Ricciardi, Paola; Colomban, Philippe y Milande, Veronique. "Non-destructive Raman characterization of Capodimonte and Buen Retiro porcelain". Journal of Raman Spectroscopy, 2008, n. ${ }^{\circ} 39$.

Romero Recio, Mirella. "Pompeii in Spanish interior decoration». Returns to Pompei. Estocolmo, 2016.

Ruggiero, Michele. Storia degli scavi di Ercolano ricomposta su' documenti superstiti. Nápoles, 1885.

SAmpaOlo, Valeria. "Insula VII». En Pompei, Pitture e Mosaici, Regio VII, Parte II. Roma, 1998, vol VII.

SÁnCHEZ JÁuregui-AlpaÑés, M. ${ }^{a}$ Dolores. "Trípode, ovvero ara antica di Marmo»; "Altra Veduta dello stesso Tripode antico di Marmo». En El Westmorland, recuerdos del Grand Tour. Madrid, 2002.

Sancho Gaspar, José Luis. El Palacio de Carlos III en el Pardo. Madrid, 2002.

SANCHO GaSPar, José Luis. "Carlos III de Monte en Monte». En Una corte para el rey. Carlos III y los Sitios Reales. Madrid, 2016.

Sancho Gaspar, José Luis. "El Salón del trono en el Palacio Real de Madrid». En Carlos III, Majestad y Ornato en los escenarios del Rey Ilustrado. Madrid, 2016. 
SANCHO GaSPar, José Luis. «Real Dormitorio». En Carlos III, Majestad y Ornato en los escenarios del Rey Ilustrado. Madrid, 2016.

SanZ De Miguel, Carlos. «El Gabinete del Óvalo de María Luisa de Parma en el Escorial: José del Castillo y sus imágenes inspiradas en la Antigüedad Clásica». Reales Sitios: Revista del Patrimonio Nacional, 2012, n. ${ }^{\circ} 192$.

SCHAEFER, Tomas. "Le "sellae curules" del Teatro di Ercolano». Cronache Ercolanesi, 1979, 9.

Simal López, Mercedes. «Isabel de Farnesio y la colección real española de escultura. Distintas noticias sobre compras, regalos, restauraciones, y el encargo del "Cuaderno de Aiello"». Archivo Español de Arte LXXIX, julio-septiembre, 2006.

Simal López, Mercedes. "Marmi per la decorazione del palazzo della Granja de San Ildefonso, residenza di Filippo V e Elisabetta Farnese». En Splendor marmoris. I colori del marmo, tra Roma e l'Europa, da Paolo III a Napoleone III. Roma, 2016.

Strazzullo, Franco. Le manifatture d'arte di Carlo di Borbone. Nápoles, 1979.

TANUCCI, Bernardo. Epistolario, IX, Roma, 1985.

TANuCCI, Bernardo. Epistolario, XIV, Nápoles, 1995.

TANuCCI, Bernardo. Epistolario, XII, Nápoles, 1997.

URREA FERNÁNDEZ, Jesús. Relaciones artísticas hispano-romanas. Madrid, 2006.

VÁzQuez Gestal, Pablo. Verso la riforma della Spagna Il Carteggio tra Maria Amalia di Sassonia e Bernardo Tanucci. Nápoles, 2016.

VEGA GonZÁLEZ, Jesusa. «Interrelaciones entre técnica y realidad en el arte de la corte borbónica, la Antichità de Ercolano esposte». Ars Longa: Cuadernos de Arte, n. ${ }^{\circ}$ 25, 2016.

VENUTI, Domenico. Spiegazione d'un servizio da tavola dipinto e modellato in porcellana nella Real Fabbrica di sua maestà il re delle Sicilie: sopra la serie de' vasi, e pitture esistenti nel Real museo Ercolanese per uso di S. M. C. Nápoles, 1782.

WinCKELMANn, Johann Joachim. Lettre de M. l'abbé Winckelmann, antiquaire de Sa Sainteté, à Monsieur le Comte de Brühl, Chambellan du roi de Pologne... sur les découvertes d'Herculanum. París, 1764. 
